\title{
Repeated Cross-Sectional Survey of Knowledge and Attitudes to Colorectal Cancer Screening in Lebanon
}

\author{
Ale J. Hejase1, Hussin Jose Hejase ${ }^{2 *}$, Hana A. Nemer ${ }^{3}$, Charifa A. Hejase ${ }^{4}$, Mohamad-Ali M. Trad ${ }^{5}$ \\ ${ }^{1}$ Lebanese American University, AKSOB, Beirut, Lebanon \\ ${ }^{2} \mathrm{Al}$ Maaref University, Beirut, Lebanon \\ ${ }^{3}$ Colorectal Cancer Awareness Association, Beirut, Lebanon \\ ${ }^{4}$ Department of Civil and Environmental Engineering, Michigan State University, Michigan, USA \\ ${ }^{5}$ College of Health and Medicine, University of Tasmania, Tasmania, Australia \\ Email: ^hhejase@mu.edu.lb, hhejase@gmail.com
}

How to cite this paper: Hejase, A.J., Hejase, H.J., Nemer, H.A., Hejase, C.A. and Trad, M.-A.M. (2020) Repeated Cross-Sectional Survey of Knowledge and Attitudes to Colorectal Cancer Screening in Lebanon. Journal of Biosciences and Medicines, 8 , 178-210.

https://doi.org/10.4236/jbm.2020.812017

Received: October 27, 2020

Accepted: December 27, 2020

Published: December 30, 2020

Copyright $\odot 2020$ by author(s) and Scientific Research Publishing Inc. This work is licensed under the Creative Commons Attribution International License (CC BY 4.0).

http://creativecommons.org/licenses/by/4.0/

\begin{abstract}
The continuous awareness campaigns about Colorectal Cancer (CRC) directed towards the Lebanese population in order to foster preventive medicine are on the rise. The impact has been positive and reported in previous research, although the number of victims is still high. This paper aims to perform a recent cross-sectional study of Lebanese residents' CRC awareness by comparing the findings of two studies carried out in the years 2016 and 2018. The samples of the current study include 1140 (2016) and 993 (2018) participants who completed a simple structured questionnaire directed to assess their knowledge of colon cancer and the behavioral intentions of obtaining CRC screening. Upon comparing results, the percentage of those who know about CRC has increased significantly from $40.4 \%$ in 2016 to $78.7 \%$ in 2018 , the proportion of respondents who believed that family history is the major risk factor for CRC did increase significantly from $47.7 \%$ in 2016 to $90.8 \%$ in 2018. Likewise, the proportions of respondents who believed that overweight, age, and stress are among the major risk factors for CRC increased from $26.9 \%, 26.7 \%$ and $11.3 \%$ in 2016 to $86.2 \%, 52.1 \%$ and $21.51 \%$ in 2018 , respectively. On the other hand, the proportions for the risk factors related to alcohol and smoking have dropped from $37.7 \%$ and $37.3 \%$ to $27.4 \%$ and $24.2 \%$, respectively. Moreover, the most important source of information for CRC was friends ( $18.4 \%$ in 2016 versus $73.8 \%$ in 2018 ), followed by family $(18.7 \%$ in 2016 versus $56.7 \%$ in 2018), and then physicians (18.9\% in 2016 and $40.2 \%$ in 2018). In fact, the efforts of the non-governmental organization (NGO) SAID (118 different major activities in the span of 3 years) did make a signif-
\end{abstract}


icant difference in what relates to CRC awareness among the Lebanese population. These findings are used to encourage and support other NGOs to adopt targeted new awareness campaigns which have proven successful, and to present evidence based on facts to government officials in the Ministry of Health to support and possibly sponsor national awareness campaigns and preventive efforts to mitigate CRC levels.

\section{Keywords}

Colorectal Cancer, Awareness, Cross-Sectional Study, Preventive Medicine, Lebanon

\section{Introduction}

Colorectal cancer (CRC) continues to be one of the principal global health care issues where recent studies have shown that it ranks second to breast cancer among females and third after lung and prostate cancers among males [1] [2]. In 2018 CRC was responsible for about $9.2 \%$ of all worldwide deaths caused by cancer ranking second with around 881,000 deaths worldwide [3]. As for Lebanon, in 2018, 1463 (8.5\%) CRC cases out of 17,298 new cancer cases were reported for both sexes thus ranking in fifth place after breast, bladder, lung and prostate cancers [4] [5]. Specifically, CRC ranked fourth among males (8.8\%) after prostate, bladder and lung cancers; and ranked second among females (8.1\%) after breast cancer. In addition, CRC accounted for $7.1 \%$ of the number of cancer mortalities with 8976 deaths out of the total number of 41,843 cancer deaths in Lebanon [4].

It is noticeable that the global cancer burden has continuously been increasing whereby in 2012, there were 14.1 million new cancer cases and around 8.2 million deaths due to cancer, then the CRC cases were around 1.36 million $(9.7 \%$ for both sexes) [6]. Later, the International Agency for Research on Cancer's press release indicated that "The global cancer burden is estimated to have risen to 18.1 million new cases and 9.6 million deaths in 2018. One in 5 men and one in 6 women worldwide develop cancer during their lifetime, and one in 8 men and one in 11 women die from the disease" [7]. In fact, the global burden of the CRC trend is expected to increase by $60 \%$ to more than 2.2 million new cases and 1.1 million deaths by 2030 [8]. Likewise, in the USA, the cases of CRC continue to increase yearly by $1 \%$ to $2.4 \%$ among people in the age range 20 to 40 years, and by $0.55 \%$ to $1.3 \%$ among people aged 40 to 55 years, respectively. This trend continues to prevail since 1980 [9] [10]. Along the aforementioned facts, Lebanon is not an exception where the incidence of different types of cancer is 179 new cases per 100,000 inhabitants and digestive cancers account for $14.1 \%$ of all types of cancer, with more than $50 \%$ of them located in the rectum and colon [11]. Further projection studies have revealed that by 2020, overall cancer will reach 361 and 312 cancer cases per 100,000 persons for males and females, re- 
spectively [12]. In fact, reported information indicates that both cancer incidence and mortality are expected to increase dramatically in the near future [5] [13].

Among those rising trends, the subject of CRC awareness remains a topic of major importance among both the medical and social communities. Indeed, various studies have shown that increasing the levels of awareness leads to an increased rate in screening for CRC and thus reduction in mortality rates [14] [15]. CRC is known to be curable if detected early, when it begins as a simple benign polyp at the interior wall of the colon [16] [17]. There is also a reduction in the medical and financial burdens of treatment [18].

CRC awareness has developed over the years and different nations have adopted campaigns and procedures to encourage people especially at ages above 45 years to undergo screening. Simple screening tests like FOBT (fecal occult blood test) and FIT (fecal immunochemical test) that look for occult blood (blood that cannot be seen with the naked eye) are becoming both very popular and affordable to identify blood in the stool which is a strong predictor to the presence of polyps or cancers in the digestive tract [19]. Thus undergoing an FOBT or FIT test can lead to the early detection of CRC cases which can be prevented or at least downstaged through colonoscopy. However, it has been reported that despite the ability to prevent the development of CRC and downstage the disease, the participation in CRC screening lags behind screening for other types of cancer [20] [21]. Screening through fecal testing, mainly fecal Occult blood test (FOBT) and fecal Immunochemical test (FIT) followed by colonoscopy for positive cases has led to an approximately $16 \%$ reduction in mortality caused by CRC [9] [22].

\section{CRC Awareness and Screening}

The usefulness of CRC screening in terms of reduction of incidence and mortality rates has been shown in randomized controlled trials since the nineties of the past century where early screening procedures were associated with a substantial reduction of CRC incidence and mortality [23]-[29]. In fact, it is well agreed that medical organizations and practice clinical guidelines highly recommend screening in average-risk populations [30] [31] [32].

A recent study by Dénes et al. [9], suggested that awareness efforts should go beyond the general public and extend specifically to health professionals who should be involved in CRC screening educational programs. The aforementioned study performed in Romania on a sample of 275 CRC patients showed that $41.5 \%$ of the patients declared that they have heard about cancer screening and only $6.5 \%$ about specific CRC screening procedures. Among those who have heard about screening, $85.1 \%$ perceived the information through mass media while the rest $14.9 \%$ got it from family, friends or colleagues. Unfortunately, the outcomes of the study indicated that health professionals did not contribute at all to informing about screening. 
Another study performed in South Carolina, USA by Brandt et al. [21], reported that even though the levels of CRC knowledge and awareness were high, overall participation in CRC screening was modest. Thus, an essential step is to elaborate on mechanisms to transform public awareness and knowledge into real screening participation because recommended screening and especially colonoscopy has prevented or downstaged CRC [33] [34]. Also Inadomi and Sonnenberg [35] assessed the effect of screening for colorectal cancer on life expectancy, and showed that CRC decreases the life expectancy of U.S. residents aged 50 to 54 years by 292 days and those aged 70 to 74 years by 70 days. Moreover, the study demonstrated that screening with fecal occult blood tests (FOBT) extends expected lifetime of the two age groups by 51 and 12 days, respectively, whereas screening with Sigmoidoscopy leads to increases of 86 and 21 days, and Colonoscopic screening increases expected lifetime by 170 and 41 days, respectively.

By the end of the first 20 years of the twentieth first century, the issue of CRC awareness continues to be a major topic of research among medical and social professionals. A recent study regarding knowledge, practice and attitude towards CRC and its screening procedures among people of Hong Kong showed that $60.9 \%$ of the people were unaware that CRC is a very common type of cancer and $91.5 \%$ responded that there wasn't any case of CRC in their family [36]. Even in first world countries like England, a recent study among English population showed that only $10 \%$ of the participants were aware of the fact that CRC is ranked third among common type of cancers and merely $46 \%$ of the people knew some symptoms and risk factors of CRC [37].

Another study done in Kuwait demonstrated that among 675 respondents, $75 \%$ of the participants had heard about CRC [38]. A similar CRC study carried out among the population of Perak state of Malaysia concluded that $38 \%$ of the 2379 participants of the study had no knowledge regarding CRC [39]. Likewise a study performed in Saudi Arabia indicated that $53.5 \%$ of the 385 surveyed Makkah residents were unaware of CRC symptoms and $92.2 \%$ never had a CRC screening test [40]. Actually, it has been reported that CRC is one of the most common cancers in Saudi Arabia being the first most common cancer among Saudi males and third among females [41]. A study conducted among people of Oman suggested that $59.6 \%$ of them were unaware of basic symptoms and risk factors of CRC and others had poor understanding of screening procedures [42]. It can be easily concluded that around the globe there is a significant fact that people lack basic knowledge regarding CRC. This trend is also very common in western countries. In reality, the lack of knowledge on CRC happens to be a noticeable barrier to screening adherence [43].

Moreover, in a study conducted in Iran assessing the practice of Iranian physicians towards CRC showed that for 71 out of 123 physicians (57.7\%), colonoscopy is the first-step screening test in average-risk individuals above 50 years; and only 22 physicians (17.9\%) designated FOBTs as the first step for the above 
50 years age group. In fact, $89.4 \%$ of the physicians recommended screening for CRC among people above the age of 50 with symptoms suggestive of CRC [44]. It is noticeable that even though Iran is experiencing a significant rise in the incidence of CRC over the recent decades [45] the aforementioned Iranian physicians study which was performed in 2018 did not include any reference to FIT CRC screening tests which are nowadays very popular in the health sectors. Despite its relatively high financial cost in comparison to other CRC pre-screening procedures, the surveyed physicians cited colonoscopy in first place followed by FOBT's. Actually, this information is similar to the Saudi physicians' survey where most of the physicians considered colonoscopy as the most effective screening test while only one-third of them agreed with FOBT [46]. Here, it is worth mentioning that the 5-year survival for persons with colorectal cancer is $64 \%$ in the United States. If the disease is detected at an early stage, the 5-year survival rate increases to $90 \%$. However, because of lack of screening programs in many countries, only $39 \%$ of colorectal cancers are diagnosed at this stage [47].

Once more, in the Middle East and specifically in Oman, a study was carried out to specifically explore nurses' and physicians' (82 nurses and 60 physicians who are clinically experienced with mean service time 9.39 years and standard deviation 6.13 years) attitudes and knowledge regarding CRC screening. The findings showed that both nurses and physicians working in primary care settings have inadequate knowledge regarding CRC screening (more than 55\% did not know the frequency of performing specific screening procedures, the upper age limit at which screening is not recommended, and the patients at high-risk for CRC).

Almost the same results were found in a Jordanian study where the knowledge of CRC among the majority (69.1\%) of nurses and physicians working in primary care settings was very poor [48]. Actually, it looks that a principal barrier to undertake CRC screening by eligible patients is the inadequate knowledge among health care professionals.

According to Tfaily et al. [49], in a study performed in Lebanon among 371 participants (more than half of them had a university level education) who were surveyed in a major health care medical center showed that $83 \%$ and $67 \%$ of participants were not aware of CRC risk factors and warning signs, respectively, $15 \%$ have previously undergone CRC screening, 56\% were aware of the necessity for screening, and $43 \%$ were willing to undergo screening. Once again, the aforementioned study did ignore existence of the popular FIT screening test where it was reported " $50 \%$ of patients who were planning to get screened in the future selected FOBT as their preferred method of screening and $42 \%$ preferred colonoscopy. The remaining $8 \%$ chose neither or no preference".

In a study performed in eight Louisiana federally qualified health centers [50] among 975 patients who were 50 years or older not up to date with CRC screening (52\% of them had low literacy, i.e. less than a $9^{\text {th }}$ grade level); the majority of participants had positive beliefs about the benefits of CRC screening using 
FOBTs, but only slightly over a third of all participants stated ever receiving a physician recommendation for CRC screening and fewer recalled being given an FOBT kit. These outcomes did not vary by literacy and clearly pointed to the limited physician recommendations.

In Hungary, the results of a study conducted among 1150 adults between the ages of 40 and 70 using quota sampling showed that $81.2 \%$ of the respondents were not well-informed about the risk factors of CRC; likewise, $79.0 \%$ were not well-informed about the symptoms of CRC, and $27.0 \%$ of respondents had not heard of CRC screening methods before [51].

In a survey administered to a representative population of the United States of America formed of 6349 participants, the term "Colonoscopy" was recognized by $80 \%$ of participants (over the age of 35 ); however, only $35 \%$ of the respondents perceived it as a major method for colon cancer screening. Gender played a major role in colon cancer knowledge. Women (42\%) were more likely than men $(27 \%)$ to understand that colonoscopy tests were for colon cancer. More women than men were aware of colonoscopy (64\% versus 36\%). Age did not play a major role in cancer knowledge. Older patients were more likely to know that colonoscopy detects colon cancer (50 - 64 years 45\%, 35 - 49 years 33\%). The youngest age group (18 - 34 years, 65\%) was less likely to have heard of colonoscopy ( $82 \%-88 \%$ in the older age groups). Employment status did not influence colon cancer knowledge [52].

"The American Cancer Society (ACS) [19] has recently issued a qualified recommendation to initiate colorectal cancer (CRC) screening starting at age 45 years in average-risk individuals. The rationale for this recommendation is that 1) US epidemiologic data show an increase in CRC incidence in individuals younger than 50 years, 2) there is concern about a birth cohort effect with individuals aged 45 to 49 showing increasing CRC incidence rate ratios since 1949, and 3) updated simulation models show a favorable balance of benefit of risk from initiating screening at an earlier age" [53].

It is well known that behind CRC screening there are two main objectives: to reduce the incidence of CRC by detecting and removing adenomas and to reduce mortality by detecting CRC at an early stage [54]. The study performed by Larsen et al. [54] completed in Denmark aimed at assessing the effectiveness of FIT tests as an early screening tool for CRC. The reported results indicated that the FIT-based CRC screening program detects CRC in earlier stages and thereby secures a better prognosis for the patients.

In order to increase awareness and direct higher percentages of the Lebanese population towards early CRC screening, the authors in conjunction with the SAID NGO CRC awareness organization exposed the citizens to a new tool of spreading awareness being a giant inflatable, walk-through colon model equipped with physical depictions of healthy tissue, polyps and CRC [55]. The research findings showed that upon comparing results before and after making the inflatable colon tour, that the use of such a tool does increase the knowledge 
of colorectal cancer and its corresponding screening practice by $49.6 \%$. A similar activity was also reported by Baasiri et al. [56] and results showed that "participants demonstrated that the inflatable colon increased participants' knowledge about CRC and its screening. It also improved their attitude toward discussing and undergoing CRC screening" (p. 171).

So, the main objective of the present study is to assess the levels of CRC awareness in Lebanon and how these levels were influenced by the massive NGO awareness campaigns that took place in a time span of three years, more precisely from the beginning of 2016 till the end of 2018. In reality, and as far as the authors know, this current study is a unique "Repeated Cross-Sectional" study that compares the Lebanese CRC public awareness over a span of three years. The newest part of this current study was administered over the Lebanese territory during the last quarter of 2018. Data was collected using a simple questionnaire via face to face interviews with more than 1000 randomly selected people. The resultant figures of the 2018 study are compared with their respective counterpart figures obtained from a study realized in 2016 [57]. The target is to assess the levels of CRC awareness improvement over 3 years (2016-2018), whereby the impact of 2017 is not tested per se but assumed to accumulate to the year after, knowing that during this period of time, continuous and massive interventions from the SAID NGO foundation, in particular, took place through direct contact lectures and demonstrations, mass media interviews, fairs, festivals, fund rising events and marathons.

This paper has its first merit from the comparative assessment of the collected and analyzed data and facts from the two studies performed in 2016 and 2018, whereby findings are statistically validated to offer a strong parametric analysis which may act as a platform for further research. The second merit is in the fact that results and outcomes enrich the current scarcity of information about the topic in Lebanon and the region. Finally, the third merit is the fact that reported improvements in CRC knowledge and awareness as presented in the previous two studies have led to materialize the government support and put into action a national campaign during the year 2019.

\section{Methodology}

This study adapts a Repeated Cross-Sectional research design. In longitudinal research studies participants are largely or entirely different on each sampling occasion and may analyze multiple variables at a given instance. Nonetheless, cross-sectional studies require less time to be set up, and may be considered for preliminary evaluations of association prior to embarking on cumbersome longitudinal-type studies [58]. Such a study is useful since it adds a dynamic component to the study of cross-sectional units and allows the investigation of time-varying relationships.

Thus, the aim of this study is to perform a recent cross-sectional study of Lebanese residents' CRC awareness and compare the findings with those from an 
earlier study [55] [57]. Repeated cross-sectional surveys are designed to give good estimates for the current population and the changes or movements that have occurred since the last survey or previous surveys.

\subsection{Sampling}

The Repeated Cross-Sectional study is based on two randomly picked samples from different locations selected from the Lebanese territory. The newest study realized during 2018 was directed to 1028 participants based on Cochran's formula [59] with $95 \%$ confidence level, $3 \%$ of error and considering the awareness level of 59.6\% achieved in 2016 [57]. Only 993 valid responses were collected to perform the 2018 study. The study that was realized in 2016 was based on a sample of 1140 participants. Both cross sectional studies were administered over the whole Lebanese territory with more emphasis on the more highly populated areas.

\subsection{Informed Consent}

The detailed purpose of the study and the informed consent [60] assuring the confidentiality and anonymity of the personal data as well as the optional participation were outlined in the first section of the survey. Study participants were largely or entirely different on each sampling occasion. In each previously conducted research, participants were clearly informed about the research objectives, and were transparently assured confidentiality of their responses, therefore all participants were willing to offer their responses and had no objections whatsoever or concerns either physically or emotionally while participating in this endeavor. No clinical trials, procedures, or medical testing were needed or performed.

\subsection{Survey Design}

A structured survey was used which included demographic data (age, gender, marital status, and education level). and based on open-ended questions and questions with a multiple-choice format. Multiple answers per question were permitted when applicable. The questionnaire was written in Arabic, which is the native language in the area of interest, and included a part pertaining to the level of participant's knowledge of said topic, followed by a demographic section. The main questions of the survey are depicted in Exhibit 1.

\subsection{Geographical Distribution}

Figure 1 depicts all the locations where between 2016 and 2018 the SAID NGO was conducting awareness campaigns for CRC in general and CRC screening in particular. The map shows the places on the Lebanese territory where for three years CRC related activities took place. Obviously, the density of activities is higher in the areas of higher population which are mainly in the capital, its suburbs and along the sea coast. The total number of CRC related activities that 
Exhibit 1. Survey questions' content.

\section{CRC Knowledge}

1) Have you ever heard of colorectal cancer?

2) Have you ever heard about early screening for colorectal cancer?

3) Do you know if any of the following increases the possibility of colorectal cancer?

Age

Family history

Tension

Smoking

Alcohol

Obesity

Not doing sport activities

Gastro-system diseases

Diabetes

4) Do you know if any of the following is a symptom of colorectal cancer?

Tummy inflation

Blood in stool

Change in bowel habit

Gases

5) What is your source for the information you have about colorectal cancer?

Physician

Nurse

Friend

Family members

Newspaper

Periodical

Media

Internet

Others, please specify

6) If your completed years of age are below 40 years, please omit this question.

After reading the following statements, please choose the only one that expresses your opinion about colorectal cancer.

a) I never thought about having an early screening test to detect colon cancer.

b) I don't think I need to do any screening test for early detection of colon cancer.

c) May be I need to do an early detection test, and I am thinking of what to do.

d) I am ready to do the early screen test for colon cancer but I haven't done it yet.

e) I have been screened for early detection of colon cancer.

7) Do you plan to get an early screening test for colon cancer even in the absence of symptoms, knowing that early screening can stop this disease?

8) Do you think that you can reduce the possibility of getting colorectal cancer?

9) Have you ever done any of the following tests?
a) FIT
b) Colonoscopy

If your answer is no, please indicate which of the following tests you are planning to have:
a) FIT
b) Colonoscopy
c) None

10) Do you have any relatives that got colon cancer?

If your answer is yes, please indicate the ages of the infected persons

\section{Respondent Demographics:}

1) Completed years of age at last birthday

2) Gender

3) Marital status

4) Residence

5) Working status

6) To whom you recur when you feel of any health related problem? 


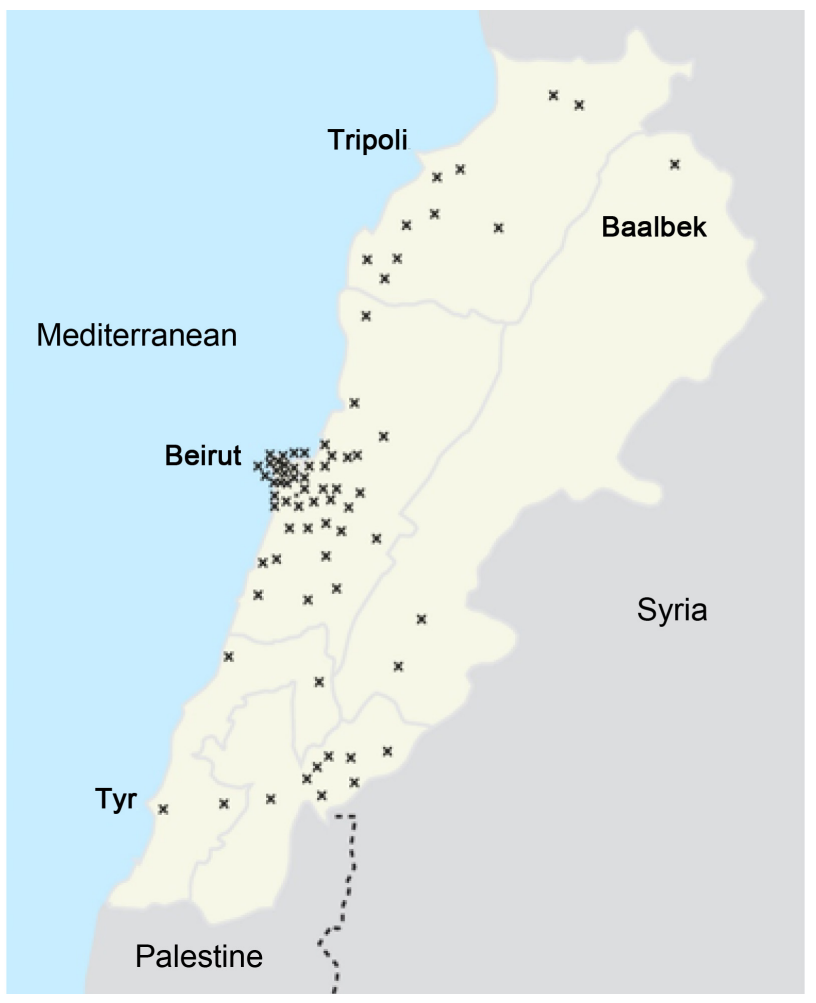

Figure 1. Geographic locations on the Lebanese territory where CRC awareness activities took place between 2016 and 2018 [55] [57].

were performed by the NGO amounts to 21 activities during 2016, 45 during 2017 and 52 during 2018. Table 1 summarizes the types and numbers of events that took place each year.

In the absence of any other extensive awareness campaign during the three years period 2016-2018, SAID NGO demonstrated a distinguished role in their activities which included: fairs, lectures, marathons, presentations, inflatable colon visits [55] and FIT tests; all having the sole aim of spreading CRC awareness across the whole Lebanese territory. In fact, the said awareness campaigns were directed to the general public including hospital patients, nurses, physicians and health government officials. Actually, the authors believe that the modest Lebanese Ministry of Health CRC campaign of March 2019 was just one of the direct outcomes from the massive work executed by the NGO [61].

\section{Results and Findings}

\subsection{Demographics of Participants}

The demographics of the participants in what relates to completed years of age at last birthday, gender, marital status, educational level and working status are provided in Table 2.

The population sample of 2016 included 1140 participants, 52\% of which were females, and a median age of 35 years. Table 2 shows that married university 
Table 1. SAID NGO distribution of awareness activities during 2016-2018.

\begin{tabular}{cccc}
\hline Activity & $\mathbf{2 0 1 6}$ & $\mathbf{2 0 1 7}$ & $\mathbf{2 0 1 8}$ \\
\hline Lectures & 10 & 29 & 30 \\
TV, Radio, Media Appearances & 3 & 6 & 14 \\
Fairs and Festivals Participation & 6 & 6 & 3 \\
Marathon Involvement & 1 & 1 & 1 \\
Fundraising: Indoor and Outdoor Events & 1 & 3 & 3 \\
Testimonial Event & & & 1 \\
Total activities per year & $\mathbf{2 1}$ & $\mathbf{4 5}$ & $\mathbf{5 2}$ \\
\hline
\end{tabular}

Source: Data reported for the first time here is accumulated by the researchers.

Table 2. Demographics of participants in 2016 and 2018.

\begin{tabular}{cccc}
\hline Demographic Characteristic & Value/Attribute & 2016 Data & 2018 Data \\
\hline \multirow{2}{*}{ Age } & Mean & 37.99 & 35.33 \\
& Standard Dev. & 0.475 & 0.459 \\
Median & 35.00 & 31.00 \\
\hline \multirow{2}{*}{ Gender } & Female & $592(52.0 \%)$ & $423(42.8 \%)$ \\
& Male & $547(48.0 \%)$ & $566(57.2 \%)$ \\
\hline \multirow{2}{*}{ Marital Status } & Single & $500(43.9 \%)$ & $481(48.6 \%)$ \\
& Married & $584(51.3 \%)$ & $429(43.3 \%)$ \\
& Divorced & $27(2.4 \%)$ & $31(3.1 \%)$ \\
& Separated & $8(0.7 \%)$ & $19(1.9 \%)$ \\
& Widowed & $19(1.7 \%)$ & $30(3.0 \%)$ \\
\hline Educational Level & Graduate studies & $228(20 \%)$ & $86(8.7 \%)$ \\
& University & $499(43.8 \%)$ & $486(49.3 \%)$ \\
& High school & $230(20.2 \%)$ & $286(29.0 \%)$ \\
& Below High school & $181(15.9 \%)$ & $127(12.9 \%)$ \\
\hline & Employed & $757(66.5 \%)$ & $572(58.4 \%)$ \\
& Unemployed & $209(18.4 \%)$ & $250(25.5 \%)$ \\
& Housewife & $151(13.3 \%)$ & $119(12.2 \%)$ \\
& Retired & $21(1.8 \%)$ & $38(3.9 \%)$ \\
\hline & &
\end{tabular}

Source: [55] [57].

level education and employed individuals dominated the group with proportions of $51.3 \%, 43.8 \%$ and $66.5 \%$ respectively. Among the participants of the 2018 sample (993 respondents), the median age was 31 years and the dominant demographics were: males (57.2\%), single (48.6\%), university education (49.3\%) and employed (58.4\%). Here, it is worth mentioning that the total number of respondents for both cross sectional studies does differ slightly under the different demographics characteristics due to the existence of few missing pieces of 
respondents' supplied data.

Table 3 summarizes the results of four different homogeneity Chi-Square tests used to determine whether frequency counts of demographics data are distributed identically across the two different populations of 2016 and 2018. For gender, we observe that $\chi^{2}(1,2128)=17.971, \mathrm{p}<0.001$. This test result indicates that the two populations of 2016 and 2018 have the same distribution of the gender variable. Moreover, the same test was performed on the other variables including marital status, educational level and the employment status leading to similar results as depicted in Table 3.

Finally, we used the Mann-Whitney test to check if the respondents' ages of the two populations (2016 and 2018) had the same distribution. The test showed that the distributions in the two populations differed significantly resulting in a Mann-Whitney $\mathrm{U}=505378.500, \mathrm{n}_{1}=1135, \mathrm{n}_{2}=978, \mathrm{P}<0.001$ two-tailed. The aforementioned outcomes indicate that the 2016 sample of size 1135 and median 35 years does have a significantly different age distribution than that of the 2018 sample of size 978 and median 31 years. The corresponding distributions are depicted in Figure 2.

Table 3. Chi-Square statistics for the homogeneity test between 2016 and 2018.

\begin{tabular}{ccc}
\hline Demographic Characteristic & \multicolumn{1}{c}{$\chi^{2}(\mathrm{df}, \mathbf{n})$} & $\mathrm{p}$-value \\
\hline Gender & $\chi^{2}(1,2128)=17.91$ & $\mathrm{p}<0.001$ \\
Marital Status & $\chi^{2}(4,2128)=21.120$ & $\mathrm{p}<0.001$ \\
Educational Level & $\chi^{2}(3,2128)=69.267$ & $\mathrm{p}<0.001$ \\
Employment Status & $\chi^{2}(3,2127)=26.312$ & $\mathrm{p}<0.001$ \\
\hline
\end{tabular}

Source: Authors' calculations.

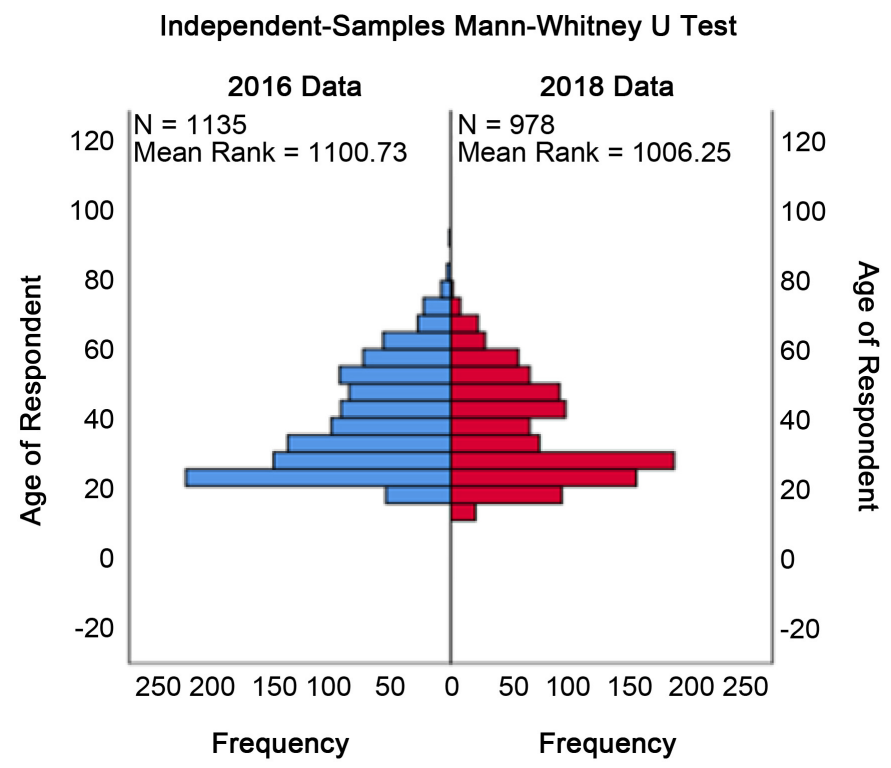

Figure 2. The age distributions for the surveys of 2016 and 2018. Source: [55] [57] Authors' calculations. 
In summary, gender, education, marital status and work status except for age distribution demonstrate that the samples of respondents corresponding to both 2016 and 2018 studies came from identical populations.

\subsection{General Results}

Statistical Product and Service Solutions (SPSS) software V.26 was used to manage and analyze the data after being verified and coded [59].

As shown in Table 4, the 2016 study revealed that the percentage of respondents who have never heard about CRC exceeded 59\%; the study also underlined the lack of knowledge on CRC screening where the percentage of respondents that have heard about it while claiming that they are familiar with CRC does not exceed 57.3\% [23]. CRC awareness did increase significantly from $40.4 \%$ in 2016 to $78.7 \%$ in $2018\left(\chi^{2}(1,2133)=318.599, \mathrm{p}<0.001\right)$. In addition, Table 4 shows the results of asking "Have you ever heard or read about colon cancer detection?" specifically to those who answered that they knew about CRC. Results show that the proportion of those who were aware of CRC screening and detection was $57.3 \%$ in 2016 which diminished to $48.0 \%$ in 2018 .

A Chi-Square test of independence was performed to compare the frequencies of the CRC screening awareness categories in 2016 and 2018. A significant dependency was found $\left(\chi^{2}(1,1234)=9.939, p=0.001\right)$, thus concluding that in fact there is a significant reduction from 2016 to 2018 in the percentage of CRC screening awareness.

As for the questions related to knowledge about CRC risk factors, Table 5 summarizes the analysis results which show a general increase in awareness of most risk factors.

Among those who are aware of colon cancer, there was an increase of those who considered age as a risk factor by about a double from $26.7 \%$ in 2016 to $52.1 \%$ in $2018\left(\chi^{2}(1,1242)=76.641, p<0.001\right)$. Likewise, the proportion of those who identified that family history is a risk factor did increase from $47.7 \%$ in 2016 to $90.8 \%$ in $2018\left(\chi^{2}(1,1242)=285.125, p<0.001\right)$. Similarly, the proportion of those who affirmed the association (stress to CRC) did increase from $11.3 \%$ in 2016 to $21.5 \%$ in 2018; and the association (overweight to CRC) did also increase from $26.9 \%$ in 2016 to $86.2 \%$ in 2018. For both variables, the Chi-Square test did confirm such significant increase.

Table 4. Survey results for CRC and CRC detection awareness.

\begin{tabular}{lccccc}
\hline \multicolumn{1}{c}{ Question } & Year & Yes & No & $\chi^{2}(\mathbf{d f}, \mathbf{n})$ & p-value \\
\hline $\begin{array}{l}\text { Have you ever heard or read } \\
\text { about colon cancer? }\end{array}$ & 2016 & $461(40.4 \%)$ & $679(59.6 \%)$ & $\chi^{2}(1,2133)=$ & $\mathrm{P}<0.001$ \\
\hline $\begin{array}{l}\text { Have you ever heard or read } \\
\text { about colon cancer detection? }\end{array}$ & 2018 & $781(78.7 \%)$ & $212(21.3 \%)$ & 318.599 & \\
\hline
\end{tabular}

Source: [55] [57] and authors' calculations. 
Table 5. Survey results for CRC risk factors.

\begin{tabular}{|c|c|c|c|c|c|}
\hline Question & Year & Yes & No & $\chi^{2}(\mathrm{df}, \mathrm{n})$ & p-value \\
\hline $\begin{array}{l}\text { Do you know if } \underline{A G E} \text { is associated } \\
\text { with increased risk of colon cancer? }\end{array}$ & 2016 & $123(26.7 \%)$ & $\begin{array}{c}338 \\
(73.3 \%) \\
374 \\
(47.9 \%)\end{array}$ & $\begin{array}{c}\chi^{2}(1,1242)= \\
76.641\end{array}$ & $\mathrm{P}<0.001$ \\
\hline $\begin{array}{l}\text { Do you know if FAMILY HISTORY } \\
\text { is associated with increased risk of } \\
\text { colon cancer? }\end{array}$ & 2016 & $\begin{array}{l}220(47.7 \%) \\
709(90.8 \%)\end{array}$ & $\begin{array}{c}241 \\
(52.3 \%) \\
72(9.2 \%)\end{array}$ & $\begin{array}{c}\chi^{2}(1,1242)= \\
285.125\end{array}$ & $\mathrm{P}<0.001$ \\
\hline $\begin{array}{l}\text { Do you know if STRESS is associated } \\
\text { with increased risk of colon cancer? }\end{array}$ & 2016 & $52(11.3 \%)$ & $\begin{array}{c}409 \\
(88.7 \%) \\
613 \\
(78.5 \%)\end{array}$ & $\begin{array}{c}\chi^{2}(1,1242)= \\
20.818\end{array}$ & $\mathrm{P}<0.001$ \\
\hline $\begin{array}{l}\text { Do you know if SMOKING is } \\
\text { associated with increased risk of } \\
\text { colon cancer? }\end{array}$ & 2016 & $172(37.3 \%)$ & $\begin{array}{c}289 \\
(62.7 \%) \\
592 \\
(75.8 \%)\end{array}$ & $\begin{array}{c}\chi^{2}(1,1242)= \\
24.167\end{array}$ & $\mathrm{P}<0.001$ \\
\hline $\begin{array}{l}\text { Do you know if } \mathrm{ALCOHOL} \text { is } \\
\text { associated with increased risk } \\
\text { of colon cancer? }\end{array}$ & 2016 & $174(37.7 \%)$ & $\begin{array}{c}287 \\
(62.3 \%) \\
567 \\
(72.6 \%)\end{array}$ & $\begin{array}{c}\chi^{2}(1,1242)= \\
14.438\end{array}$ & $\mathrm{P}<0.001$ \\
\hline $\begin{array}{l}\text { Do you know if OBESITY is } \\
\text { associated with increased risk } \\
\text { of colon cancer? }\end{array}$ & 2018 & $673(86.2 \%)$ & $\begin{array}{c}337 \\
(73.1 \%) \\
108 \\
(13.8 \%)\end{array}$ & $\begin{array}{c}\chi^{2}(1,1242)= \\
442.972\end{array}$ & $\mathrm{P}<0.001$ \\
\hline
\end{tabular}

Source: [55] [57] and authors' calculations.

On the other hand, results of asking those who are aware of colon cancer if smoking and alcohol are factors associated with CRC show that the proportion of those who affirmed the association (smoking to CRC) and (alcohol to CRC) did decrease from $37.3 \%$ in 2016 to $24.2 \%$ in 2018 and from $37.7 \%$ in 2016 to $27.4 \%$ in 2018, respectively. Both results were confirmed with the Chi-Square test of independence as shown in Table 5.

In summary, the Lebanese population is becoming more aware that age, family history, stress and obesity are risk factors that are associated with increased risk of colon cancer; while smoking and alcohol are becoming less popular in what relates to their association with CRC risk.

As for symptoms of CRC, Table 6 discloses that in general the awareness about the symptoms of CRC has significantly increased from 2016 to 2018. In fact, reported results show that among those who are aware of colon cancer, the percentage who believes that abdominal distension (bloating), blood in stool, change in bowel habits, and gases are CRC symptoms did increase from $36.7 \%$ in 2016 to $61.8 \%$ in 2018 for the first, from $58.4 \%$ in 2016 to $94.4 \%$ in 2018 for the second, from $28.6 \%$ in 2016 to $69.0 \%$ in 2018, and from $15.2 \%$ in 2016 to $46.5 \%$ 
Table 6. 2016 and 2018 survey results for symptoms associated with colon cancer.

\begin{tabular}{|c|c|c|c|c|c|}
\hline Question & Year & Yes & No & $\chi^{2}(\mathrm{df}, \mathrm{n})$ & p-value \\
\hline $\begin{array}{l}\text { Do you know if ABDOMINAL } \\
\text { DISTENSION is a symptom } \\
\text { of colon cancer? }\end{array}$ & 2018 & $\begin{array}{c}169 \\
(36.7 \%) \\
\\
482 \\
(61.8 \%)\end{array}$ & $\begin{array}{c}292 \\
(63.3 \%) \\
298 \\
(38.2 \%)\end{array}$ & $\begin{array}{c}\chi^{2}(1,1241)= \\
73.402\end{array}$ & $\mathrm{P}<0.001$ \\
\hline $\begin{array}{l}\text { Do you know if BLOOD IN STOOL } \\
\text { is a symptom of colon cancer? }\end{array}$ & 2016 & $\begin{array}{c}269 \\
(58.4 \%) \\
736 \\
(94.4 \%)\end{array}$ & $\begin{array}{c}192 \\
(41.6 \%) \\
44(5.6 \%)\end{array}$ & $\begin{array}{c}\chi^{2}(1,1241)= \\
243.936\end{array}$ & $\mathrm{P}<0.001$ \\
\hline $\begin{array}{l}\text { Do you know if CHANGE IN } \\
\text { BOWEL HABITS is a symptom } \\
\text { of colon cancer? }\end{array}$ & 2018 & $\begin{array}{c}132 \\
(28.6 \%) \\
538 \\
(69.0 \%)\end{array}$ & $\begin{array}{c}329 \\
(71.4 \%) \\
242 \\
(31.0 \%)\end{array}$ & $\begin{array}{c}\chi^{2}(1,1241)= \\
189.823\end{array}$ & $\mathrm{P}<0.001$ \\
\hline $\begin{array}{l}\text { Do you know if GASES is a } \\
\text { symptom of colon cancer? }\end{array}$ & 2016 & $\begin{array}{c}70 \\
(15.2 \%) \\
363 \\
(46.5 \%)\end{array}$ & $\begin{array}{c}391 \\
(84.8 \%) \\
417 \\
(53.5 \%)\end{array}$ & $\begin{array}{c}\chi^{2}(1,1241)= \\
125.388\end{array}$ & $\mathrm{P}<0.001$ \\
\hline
\end{tabular}

Source: [55] [57] and authors' calculations.

in 2018 for the fourth. Table 6 reports the corresponding Chi-Square tests of independence results which affirm that there is significant increase from 2016 to 2018 in the percentage of those who believe that abdominal distension, blood in stool, change in bowel habits and gases are CRC symptoms.

Table 7 presents the respondents' answers for their main sources of information in what relates to knowledge about CRC. The proportion of those who chose "doctor," "nurse," "friend" and "family" did increase from 2016 to 2018. Chi-Square tests of independence were calculated and significant dependency was found for relying on a doctor, friend and family, thus concluding that in fact there is a significant increase from 2016 to 2018 . However, the Chi-Square test of independence for significant dependency failed for relying on "nurse," thus concluding that in fact there is no significant increase from 2016 to 2018 in the percentage of those who rely on a nurse as their CRC source of information.

Furthermore, results of asking those who are aware of colon cancer if a "newspaper," "magazine," and "media" are their CRC source of information show that the proportion did increase slightly from 2016 to 2018 for relying on "newspaper" and "magazine" but decrease for "media". Chi-Square tests of independence point at a significant increase from 2016 to 2018 in the percentage of those who rely on newspapers while a significant decrease for those relying on media as their CRC source of information, in addition that a no significant increase at $5 \%$ level of significance was found of those who rely on magazines as their CRC source of information. Here, it is worth to notice that the results reported for newspapers and magazines agree with the work of Hejase et al. [62] [63] which reported that Lebanon is among the countries which are suffering 
Table 7. 2016 and 2018 surveys answers to sources of CRC information.

\begin{tabular}{|c|c|c|c|c|c|}
\hline Question & Year & Yes & No & $\chi^{2}(\mathrm{df}, \mathrm{n})$ & $p$-value \\
\hline $\begin{array}{l}\text { My CRC source of information } \\
\text { is: DOCTOR }\end{array}$ & 2018 & $\begin{array}{c}87 \\
(18.9 \%) \\
314 \\
(40.2 \%)\end{array}$ & $\begin{array}{c}374 \\
(81.1 \%) \\
467 \\
(59.8 \%)\end{array}$ & $\begin{array}{c}\chi^{2}(1,1242)= \\
60.344\end{array}$ & $\mathrm{P}<0.001$ \\
\hline $\begin{array}{l}\text { My CRC source of information } \\
\text { is: NURSE }\end{array}$ & 2016 & $\begin{array}{c}25 \\
(5.4 \%) \\
60 \\
(7.7 \%)\end{array}$ & $\begin{array}{c}436 \\
(94.6 \%) \\
721 \\
(92.3 \%)\end{array}$ & $\begin{array}{c}\chi^{2}(1,1242)= \\
2.321\end{array}$ & $\mathrm{P}=0.128$ \\
\hline $\begin{array}{l}\text { My CRC source of information } \\
\text { is: } \underline{\text { FRIEND }}\end{array}$ & 2016 & $\begin{array}{c}85 \\
(18.4 \%) \\
576 \\
(73.8 \%)\end{array}$ & $\begin{array}{c}376 \\
(81.6 \%) \\
205 \\
(26.2 \%)\end{array}$ & $\begin{array}{c}\chi^{2}(1,1242)= \\
356.252\end{array}$ & $\mathrm{P}<0.001$ \\
\hline $\begin{array}{l}\text { My CRC source of information } \\
\text { is: FAMILY }\end{array}$ & 2016 & $\begin{array}{c}86 \\
(18.7 \%) \\
443 \\
(56.7 \%)\end{array}$ & $\begin{array}{c}375 \\
(81.3 \%) \\
338 \\
(43.3 \%)\end{array}$ & $\begin{array}{c}\chi^{2}(1,1242)= \\
171.801\end{array}$ & $\mathrm{P}<0.001$ \\
\hline $\begin{array}{l}\text { My CRC source of information } \\
\text { is: NEWSPAPER }\end{array}$ & 2016 & $\begin{array}{c}9 \\
(2.0 \%) \\
55 \\
(7.0 \%)\end{array}$ & $\begin{array}{c}452 \\
(98.0 \%) \\
726 \\
(93.0 \%)\end{array}$ & $\begin{array}{c}\chi^{2}(1,1242)= \\
15.367\end{array}$ & $\mathrm{P}<0.001$ \\
\hline $\begin{array}{l}\text { My CRC source of information } \\
\text { is: MAGAZINE }\end{array}$ & 2016 & $\begin{array}{c}16 \\
(3.5 \%) \\
45 \\
(5.8 \%)\end{array}$ & $\begin{array}{c}445 \\
(96.5 \%) \\
736 \\
(94.2 \%)\end{array}$ & $\begin{array}{c}\chi^{2}(1,1242)= \\
3.258\end{array}$ & $\mathrm{P}=0.071$ \\
\hline $\begin{array}{l}\text { My CRC source of information } \\
\text { is: MEDIA }\end{array}$ & 2016 & $\begin{array}{c}104 \\
(22.6 \%) \\
107 \\
(13.7 \%)\end{array}$ & $\begin{array}{c}357 \\
(77.4 \%) \\
674 \\
(86.3 \%)\end{array}$ & $\begin{array}{c}\chi^{2}(1,1242)= \\
16.133\end{array}$ & $\mathrm{P}<0.001$ \\
\hline $\begin{array}{l}\text { My CRC source of information } \\
\text { is: INTERNET }\end{array}$ & 2016 & $\begin{array}{c}138 \\
(29.9 \%) \\
\\
146 \\
(18.7 \%)\end{array}$ & $\begin{array}{c}323 \\
(70.1 \%) \\
635 \\
(81.3 \%)\end{array}$ & $\begin{array}{c}\chi^{2}(1,1242)= \\
20.768\end{array}$ & $\mathrm{P}<0.001$ \\
\hline $\begin{array}{l}\text { My CRC source of information } \\
\text { is: OTHERS }\end{array}$ & 2016 & $\begin{array}{c}18 \\
(3.9 \%) \\
1 \\
(0.1 \%)\end{array}$ & $\begin{array}{c}439 \\
(96.1 \%) \\
729 \\
(99.9 \%)\end{array}$ & $\begin{array}{c}\chi^{2}(1,1242)= \\
25.790\end{array}$ & $\mathrm{P}<0.001$ \\
\hline
\end{tabular}

Source: [55] [57] and authors' calculations.

from a decline in reading habits and therefore missing information about potential issues.

The proportion of those who chose "Internet" and "others" did decrease from 2016 to 2018 and the Chi-Square test of independence presents a significant decrease from 2016 to 2018 in the percentage of those who rely on the Internet as 
well as on other sources as their CRC source of information.

Another CRC research evaluation issue was related to screening tests done or planned to be done in the future. Under this aspect the questions and results are presented in Table 8. The proportion of those who have undergone a FIT test did modestly increase from $4.8 \%$ in 2016 to $5.9 \%$ in 2018 . A Chi-Square test of independence was calculated and a non-significant dependency was found $\left(\chi^{2}(1\right.$, $1242)=0.700, p=0.403$ ), thus concluding that in fact there is no significant increase from 2016 to 2018 in the percentage of those who did a FIT test for CRC screening.

In addition, Table 8 reveals the results of asking those who are aware of colon cancer if they have done a colonoscopy where it is noticeable that the proportion of those who have undertaken a colonoscopy did significantly decrease from $10.8 \%$ in 2016 to $4.7 \%$ in 2018 . As for the future planned CRC screening intentions, the proportion of those who informed that they intended to undertake a colonoscopy did decrease from $22.7 \%$ in 2016 to $11.4 \%$ in 2018 , and its Chi-Square test of independence pointed at a significant decrease from 2016 to 2018 in the percentage of those who plan to consider a colonoscopy test for CRC screening.

Finally, for the results of asking those who are aware of colon cancer if they have any future intentions to undergo a FIT test, Table 8 discloses that the proportion of those who intend to undertake a FIT did increase considerably from $22.0 \%$ in 2016 to $66.5 \%$ in 2018 . The Chi-Square test of independence does support that there is a significant increase from 2016 to 2018 in the percentage of

Table 8. Respondents' answers on performed and Plan-To-Do CRC tests.

\begin{tabular}{|c|c|c|c|c|c|}
\hline Question & Year & Yes & No & $\chi^{2}(\mathrm{df}, \mathrm{n})$ & p-value \\
\hline \multirow{2}{*}{ I did a Blood in stool FIT test? } & 2016 & $22(4.8 \%)$ & $\begin{array}{c}439 \\
(95.2 \%)\end{array}$ & \multirow{2}{*}{$\begin{array}{c}\chi^{2}(1,1242)= \\
0.700\end{array}$} & \multirow{2}{*}{$P=0.403$} \\
\hline & 2018 & $46(5.9 \%)$ & $\begin{array}{c}735 \\
(94.1 \%)\end{array}$ & & \\
\hline \multirow{2}{*}{ I did a COLONOSCOPY test? } & 2016 & $\begin{array}{c}50 \\
(10.8 \%)\end{array}$ & $\begin{array}{c}411 \\
(89.2 \%)\end{array}$ & \multirow{2}{*}{$\begin{array}{c}\chi^{2}(1,1242)= \\
16.605\end{array}$} & \multirow{2}{*}{$\mathrm{P}<0.001$} \\
\hline & 2018 & $37(4.7 \%)$ & $\begin{array}{c}744 \\
(95.3 \%)\end{array}$ & & \\
\hline \multirow{2}{*}{ I plan to do a COLONOSCOPY test. } & 2016 & $\begin{array}{c}104 \\
(22.7 \%)\end{array}$ & $\begin{array}{c}354 \\
(77.3 \%)\end{array}$ & \multirow{2}{*}{$\begin{array}{c}\chi^{2}(1,1239)= \\
28.091\end{array}$} & \multirow{2}{*}{$\mathrm{P}<0.001$} \\
\hline & 2018 & $\begin{array}{c}89 \\
(11.4 \%)\end{array}$ & $\begin{array}{c}692 \\
(88.6 \%)\end{array}$ & & \\
\hline \multirow{2}{*}{ I plan to do a FIT test. } & 2016 & $\begin{array}{c}101 \\
(22.0 \%)\end{array}$ & $\begin{array}{c}358 \\
(78.0 \%)\end{array}$ & \multirow{2}{*}{$\begin{array}{c}\chi^{2}(1,1240)= \\
228.467\end{array}$} & \multirow{2}{*}{$\mathrm{P}<0.001$} \\
\hline & 2018 & $\begin{array}{c}519 \\
(66.5 \%)\end{array}$ & $\begin{array}{c}262 \\
(33.5 \%)\end{array}$ & & \\
\hline
\end{tabular}

Source: [55] [57] and authors' calculations. 
those who plan to consider a FIT test for CRC screening. For the SAID NGO, in particular, and other concerned NGOs, in general, this should mark a distinguished achievement since the FIT test that was rarely known back in 2016 became much more popular due to the intensive awareness campaigns the NGO executed across Lebanon (The Fecal Occult Blood Test-FOBT-was the most popular prior to 2016).

The answers to the question, "Do you have relatives with colorectal cancer?" are depicted in Table 9 which reveals that the proportion of those respondents who had relatives suffering from CRC did decrease from $22.8 \%$ in 2016 down to only $9.9 \%$ in 2018. A Chi-Square test of independence was calculated and a significant dependency was found $\left(\chi^{2}(1,1221)=38.040, p<0.001\right)$, thus concluding that there is a significant decrease from 2016 to 2018 in the percentage of those who have relatives diagnosed with CRC.

Similarly, the respondents were asked to provide the age of their relatives who suffer from CRC. Table 10 gives a brief summary of the corresponding statistics. Certainly a research question arises as: "Is there a difference between the mean ages of relatives with CRC as detected in 2016 and 2018?" A Mann-Whitney U test reveals that there is a significant difference $(U=1998.5, p<0.001)$ between the group of CRC relatives in 2016 compared to the group of CRC relatives in 2018. The median in 2016 was 57 years compared to 67 years in 2018 suggesting that the median age of CRC diagnosed relatives has indeed increased. Thus the test rejects the null hypothesis that the distribution of ages of relatives with CRC is the same across both cross-sectional studies (2016 and 2018). It is a very optimistic feature that the distribution of ages of CRC patients has relatively increased over the span of three years.

Table 9. The answers to "Do you have relatives with colorectal cancer?",

\begin{tabular}{lccccc}
\hline \multicolumn{1}{c}{ Question } & Year & Yes & No & $\chi^{2}(\mathbf{d f}, \mathrm{n})$ & p-value \\
\hline & 2016 & $\begin{array}{c}105 \\
(22.8 \%)\end{array}$ & $\begin{array}{c}356 \\
(77.2 \%)\end{array}$ & & \\
& & & $\chi^{2}(1,1221)=$ & $\mathrm{P}<$ \\
$\begin{array}{l}\text { Do you have relatives with } \\
\text { Colorectal Cancer? }\end{array}$ & 2018 & 75 & 685 & 38.040 & 0.001 \\
& & $(9.9 \%)$ & $(90.1 \%)$ & & \\
\hline
\end{tabular}

Source: [55] [57] and authors' calculations.

Table 10. Basic statistics for the respondents' relatives who suffer from CRC.

\begin{tabular}{cccc}
\hline Characteristic & Value/Attribute & 2016 Data & 2018 Data \\
\hline & Mean & 56.17 & 66.56 \\
Age of relative with CRC & Standard Error & 1.170 & 1.205 \\
& Median & 57.00 & 67.00 \\
& Std. Deviation & 11.993 & 10.432 \\
\hline
\end{tabular}

Source: [55] [57] and authors' calculations. 


\subsection{CRC Awareness versus Demographic Variables}

\subsubsection{CRC Awareness and Gender Results}

Gender has always played a principal role in colon cancer knowledge. In the 2016 survey, as depicted in Table 11, 46.6\% of the females compared to $33.6 \%$ of the males were familiar with colon cancer. These figures in 2018 became $73.5 \%$ and $82.5 \%$ for females and males, respectively. The Chi-Square test of independence was used to test if CRC awareness is related to gender. Table 11 reveals that for the survey of 2016, gender and familiarity with CRC are significantly dependent where females dominated, this outcome changed in the survey of 2018 where males were significantly more acquainted.

Likewise, for those respondents who were familiar with CRC, in being aware of CRC detection, female percentage (60.9\%) overtook that of males $(51.6 \%)$ in the survey of 2016; however, in the survey of 2018 male familiarity with CRC detection (48.8\%) got slightly beyond the females percentage $(46.6 \%)$. The Chi-Square test to assess if gender and awareness of CRC detection are independent showed that for the 2016 survey $\chi^{2}(1,460)=3.849$ with a $\mathrm{p}$-value $=$ 0.050 ; and for the 2018 survey this test gave $\chi^{2}(1,772)=0.371$ with a $\mathrm{p}$-value $=$ 0.543 indicating that at $5 \%$ level of significance, the response to "Have you ever heard or read about colon cancer detection?" was marginally independent of the gender of the respondent.

It looks that from 2016 to 2018, the population understanding of CRC has grown where back in 2016 females were more familiar than males, then by 2018 roles have changed. Similarly, for those acquainted with CRC, the surveys do not show any gender dependency when the familiarity with CRC detection is considered.

Table 11. Gender analysis for CRC awareness and CRC detection awareness for those familiar with CRC.

\begin{tabular}{|c|c|c|c|c|c|c|}
\hline Question & Year & Gender & Yes & No & $\chi^{2}(\mathrm{df}, \mathrm{n})$ & $\mathrm{p}$-value \\
\hline \multirow{2}{*}{$\begin{array}{l}\text { Have you ever heard or read } \\
\text { about colon cancer? }\end{array}$} & 2016 & Female & $\begin{array}{c}276 \\
(46.6 \%) \\
184 \\
(33.6 \%)\end{array}$ & $\begin{array}{c}316 \\
(53.4 \%) \\
363 \\
(66.4 \%)\end{array}$ & $\begin{array}{c}\chi^{2}(1,1139)= \\
19.907\end{array}$ & $\mathrm{P}<0.001$ \\
\hline & 2018 & Female & $\begin{array}{c}311 \\
(73.5 \%) \\
467 \\
(82.5 \%)\end{array}$ & $\begin{array}{c}112 \\
(26.5 \%) \\
99 \\
(17.5 \%)\end{array}$ & $\begin{array}{c}\chi^{2}(1,989)= \\
11.648\end{array}$ & $\mathrm{P}=0.001$ \\
\hline \multirow{2}{*}{$\begin{array}{l}\text { Have you ever heard or read } \\
\text { about colon cancer detection? }\end{array}$} & 2016 & Female & $\begin{array}{c}168 \\
(60.9 \%) \\
95 \\
(51.6 \%)\end{array}$ & $\begin{array}{c}108 \\
(39.1 \%) \\
89 \\
(48.4 \%)\end{array}$ & $\begin{array}{c}\chi^{2}(1,460)= \\
3.849\end{array}$ & $\mathrm{P}=0.050$ \\
\hline & 2018 & Female & $\begin{array}{c}143 \\
(46.6 \%) \\
227 \\
(48.8 \%)\end{array}$ & $\begin{array}{c}164 \\
(53.4) \\
238 \\
(51.2 \%)\end{array}$ & $\begin{array}{c}\chi^{2}(1,772)= \\
0.371\end{array}$ & $\mathrm{P}=0.543$ \\
\hline
\end{tabular}

Source: [55] [57] and authors' calculations. 


\subsubsection{CRC Awareness and Education Level Results}

Considering education, a Chi-Square test of independence for the 2016 data, resulted in $\chi^{2}(3,460)=27.809$ with a $\mathrm{p}$-value $<0.001$ indicating that the response to "Have you ever heard or read about colon cancer detection?" was in fact dependent on the level of education with more educated respondents having higher familiarity with CRC detection. Similarly, for the data corresponding to 2018. It is worth noticing that this feature (higher CRC detection awareness among educated population) did not change through time (see Table 12 for details).

Table 12. Education analysis for CRC awareness and CRC detection awareness for those familiar with CRC.

\begin{tabular}{|c|c|c|c|c|c|c|}
\hline Question & Year & Education & Yes & No & $\chi^{2}(\mathrm{df}, \mathrm{n})$ & p-value \\
\hline \multirow{8}{*}{$\begin{array}{l}\text { Have you ever heard or } \\
\text { read about colon cancer? }\end{array}$} & \multirow{4}{*}{2016} & Graduate & $\begin{array}{c}113 \\
(49.6 \%)\end{array}$ & $\begin{array}{c}115 \\
(50.4 \%)\end{array}$ & \multirow{4}{*}{$\begin{array}{c}\chi^{2}(3,1138)= \\
27.683\end{array}$} & \multirow{4}{*}{$\mathrm{P}<0.001$} \\
\hline & & University & $\begin{array}{c}216 \\
(43.3 \%)\end{array}$ & $\begin{array}{c}283 \\
(56.7 \%)\end{array}$ & & \\
\hline & & Secondary & $\begin{array}{c}85 \\
(37.0 \%)\end{array}$ & $\begin{array}{c}145 \\
(63.0 \%)\end{array}$ & & \\
\hline & & Basic & $\begin{array}{c}46 \\
(25.4 \%)\end{array}$ & $\begin{array}{c}135 \\
(74.6 \%)\end{array}$ & & \\
\hline & \multirow{4}{*}{2018} & Graduate & $\begin{array}{c}76 \\
(88.4 \%)\end{array}$ & $\begin{array}{c}10 \\
(11.6 \%)\end{array}$ & \multirow{4}{*}{$\begin{array}{c}\chi^{2}(3,985)= \\
123.020\end{array}$} & \multirow{4}{*}{$\mathrm{P}<0.001$} \\
\hline & & University & $\begin{array}{c}428 \\
(88.1 \%)\end{array}$ & $\begin{array}{c}58 \\
(11.9 \%)\end{array}$ & & \\
\hline & & Secondary & $\begin{array}{c}216 \\
(75.5 \%)\end{array}$ & $\begin{array}{c}70 \\
(24.5 \%)\end{array}$ & & \\
\hline & & Basic & $\begin{array}{c}56 \\
(44.1 \%)\end{array}$ & $\begin{array}{c}71 \\
(55.9 \%)\end{array}$ & & \\
\hline \multirow{8}{*}{$\begin{array}{l}\text { Have you ever heard or } \\
\text { read about colon cancer } \\
\text { detection? }\end{array}$} & \multirow{4}{*}{2016} & Graduate & $\begin{array}{c}86 \\
(76.1 \%)\end{array}$ & $\begin{array}{c}27 \\
(23.4 \%)\end{array}$ & \multirow{4}{*}{$\begin{array}{c}\chi^{2}(3,460)= \\
27.809\end{array}$} & \multirow{4}{*}{$\mathrm{P}<0.001$} \\
\hline & & University & $\begin{array}{c}121 \\
(56.0 \%)\end{array}$ & $\begin{array}{c}95 \\
(44.0 \%)\end{array}$ & & \\
\hline & & Secondary & $\begin{array}{c}36 \\
(42.4 \%)\end{array}$ & $\begin{array}{c}49 \\
(57.5 \%)\end{array}$ & & \\
\hline & & Basic & $\begin{array}{c}20 \\
(43.5 \%)\end{array}$ & $\begin{array}{c}26 \\
(56.5 \%)\end{array}$ & & \\
\hline & \multirow{4}{*}{2018} & Graduate & $\begin{array}{c}38 \\
(50.7 \%)\end{array}$ & $\begin{array}{c}37 \\
(49.3 \%)\end{array}$ & \multirow{4}{*}{$\begin{array}{c}\chi^{2}(3,771)= \\
11.345\end{array}$} & \multirow{4}{*}{$\mathrm{P}=0.010$} \\
\hline & & University & $\begin{array}{c}223 \\
(52.6 \%)\end{array}$ & $\begin{array}{c}201 \\
(47.4 \%)\end{array}$ & & \\
\hline & & Secondary & $\begin{array}{c}85 \\
(39.4 \%)\end{array}$ & $\begin{array}{c}131 \\
(60.6 \%)\end{array}$ & & \\
\hline & & Basic & $\begin{array}{c}23 \\
(41.1 \%)\end{array}$ & $\begin{array}{c}33 \\
(58.4 \%)\end{array}$ & & \\
\hline
\end{tabular}

Source: [55] [57] and authors' calculations. 


\subsubsection{CRC Awareness and Marital Status Results}

Considering the marital status of the respondents and its influence on CRC knowledge and awareness of screening, Table 13 presents the Chi-Square tests of independence for the 2016 and 2018 data. Both outcomes emphasize the dependency between CRC awareness and marital status where married individuals continue to be more knowledgeable about the topic. Moreover, if knowledge exists among the respondents, then the survey of 2016 indicated that married (55.8\%) were more to be aware of CRC detection but the Chi-Square test ( $\mathrm{p}=$ 0.749) did not support that, thus concluding that in the 2016 marital status and knowledge about CRC detection among CRC aware individuals are independent. This aspect did change in the survey of 2018 where Chi-Square results indicate that the response to "Have you ever heard or read about colon cancer detection?" is dependent (at 5\% level of significance) on the marital status where the status married and others (divorced, separated or widowed) have a significant influence on familiarity with CRC detection.

Table 13. Influence of marital status on CRC awareness (others means divorced, separated or widowed).

\begin{tabular}{|c|c|c|c|c|c|c|}
\hline Question & Year & Education & Yes & No & $\chi^{2}(\mathrm{df}, \mathrm{n})$ & $\mathrm{p}$-value \\
\hline \multirow{6}{*}{$\begin{array}{l}\text { Have you ever heard or } \\
\text { read about colon cancer? }\end{array}$} & & Single & $\begin{array}{c}182 \\
(36.4 \%)\end{array}$ & $\begin{array}{c}318 \\
(63.6 \%)\end{array}$ & \multirow{3}{*}{$\begin{array}{c}\chi^{2}(2,1138)= \\
8.559\end{array}$} & \multirow{3}{*}{$\mathrm{P}=0.014$} \\
\hline & 2016 & Married & $\begin{array}{c}260 \\
(44.5 \%)\end{array}$ & $\begin{array}{c}324 \\
(55.5 \%)\end{array}$ & & \\
\hline & & Others & $\begin{array}{c}18 \\
(33.3 \%)\end{array}$ & $\begin{array}{c}36 \\
(66.7 \%)\end{array}$ & & \\
\hline & \multirow{3}{*}{2018} & Single & $\begin{array}{c}334 \\
(69.4 \%)\end{array}$ & $\begin{array}{c}147 \\
(30.6 \%)\end{array}$ & \multirow{3}{*}{$\begin{array}{c}\chi^{2}(2,990)= \\
49.463\end{array}$} & \multirow{3}{*}{$\mathrm{P}<0.001$} \\
\hline & & Married & $\begin{array}{c}380 \\
(88.6 \%)\end{array}$ & $\begin{array}{c}49 \\
(11.4 \%)\end{array}$ & & \\
\hline & & Others & $\begin{array}{c}64 \\
(80.0 \%)\end{array}$ & $\begin{array}{c}16 \\
(20.0 \%)\end{array}$ & & \\
\hline \multirow{6}{*}{$\begin{array}{l}\text { Have you ever heard or } \\
\text { read about colon cancer } \\
\text { detection? }\end{array}$} & \multirow{3}{*}{2016} & Single & $\begin{array}{c}108 \\
(59.3 \%)\end{array}$ & $\begin{array}{c}74 \\
(40.7 \%)\end{array}$ & \multirow{3}{*}{$\begin{array}{c}\chi^{2}(3,460)= \\
0.578\end{array}$} & \multirow{3}{*}{$\mathrm{P}=0.749$} \\
\hline & & Married & $\begin{array}{c}145 \\
(55.8 \%)\end{array}$ & $\begin{array}{c}115 \\
(44.2 \%)\end{array}$ & & \\
\hline & & Others & $\begin{array}{c}10 \\
(55.6 \%)\end{array}$ & $\begin{array}{c}8 \\
(44.4 \%)\end{array}$ & & \\
\hline & \multirow{3}{*}{2018} & Single & $\begin{array}{c}136 \\
(41.2 \%)\end{array}$ & $\begin{array}{c}194 \\
(58.8 \%)\end{array}$ & \multirow{3}{*}{$\begin{array}{c}\chi^{2}(2,772)= \\
11.565\end{array}$} & \multirow{3}{*}{$\mathrm{P}=0.003$} \\
\hline & & Married & $\begin{array}{c}196 \\
(51.9 \%)\end{array}$ & $\begin{array}{c}182 \\
(48.1 \%)\end{array}$ & & \\
\hline & & Others & $\begin{array}{c}38 \\
(59.4 \%)\end{array}$ & $\begin{array}{c}26 \\
(40.6 \%)\end{array}$ & & \\
\hline
\end{tabular}

Source: [55] [57] and authors' calculations. 


\subsubsection{CRC Awareness and Work Status Results}

Table 14 depicts the results for CRC awareness in comparison with work status. Chi-Square test results point to the outcome that the work status and being aware of CRC are dependent where it is observed that in the 2016 survey, the unemployed were the less acquainted (only $27.8 \%$ of the unemployed knew about CRC). Even though the acquaintance for CRC did increase by 2018, the unemployed continued to be the most unaware of CRC (in 2018 only $60.4 \%$ of the unemployed knew about CRC while in all other categories the percentage exceeded $82 \%$ ).

Table 14. CRC awareness and employment status.

\begin{tabular}{|c|c|c|c|c|c|c|}
\hline Question & Year & Education & Yes & No & $\chi^{2}(\mathrm{df}, \mathrm{n})$ & p-value \\
\hline \multirow{8}{*}{$\begin{array}{l}\text { Have you ever heard or } \\
\text { read about colon cancer? }\end{array}$} & \multirow{4}{*}{2016} & Employed & $\begin{array}{c}323 \\
(42.7 \%)\end{array}$ & $\begin{array}{c}434 \\
(57.3 \%)\end{array}$ & \multirow{4}{*}{$\begin{array}{c}\chi^{2}(3,1138)= \\
18.296\end{array}$} & \multirow{4}{*}{$\mathrm{P}<0.001$} \\
\hline & & Unemployed & $\begin{array}{c}58 \\
(27.8 \%)\end{array}$ & $\begin{array}{c}151 \\
(72.2 \%)\end{array}$ & & \\
\hline & & Housewife & $\begin{array}{c}71 \\
(47.0 \%)\end{array}$ & $\begin{array}{c}80 \\
(53.0 \%)\end{array}$ & & \\
\hline & & Retired & $\begin{array}{c}8 \\
(38.1 \%)\end{array}$ & $\begin{array}{c}13 \\
(61.9 \%)\end{array}$ & & \\
\hline & \multirow{4}{*}{2018} & Employed & $\begin{array}{c}487 \\
(85.1 \%)\end{array}$ & $\begin{array}{c}85 \\
(14.9 \%)\end{array}$ & \multirow{4}{*}{$\begin{array}{c}\chi^{2}(3,979)= \\
67.561\end{array}$} & \multirow{4}{*}{$\mathrm{P}<0.001$} \\
\hline & & Unemployed & $\begin{array}{c}151 \\
(60.4 \%)\end{array}$ & $\begin{array}{c}99 \\
(39.6 \%)\end{array}$ & & \\
\hline & & Housewife & $\begin{array}{c}98 \\
(82.4 \%)\end{array}$ & $\begin{array}{c}21 \\
(17.6 \%)\end{array}$ & & \\
\hline & & Retired & $\begin{array}{c}34 \\
(89.5 \%)\end{array}$ & $\begin{array}{c}4 \\
(10.5 \%)\end{array}$ & & \\
\hline \multirow{8}{*}{$\begin{array}{l}\text { Have you ever heard or } \\
\text { read about colon cancer } \\
\text { detection? }\end{array}$} & \multirow{4}{*}{2016} & Employed & $\begin{array}{c}179 \\
(55.4 \%)\end{array}$ & $\begin{array}{c}144 \\
(44.6 \%)\end{array}$ & \multirow{4}{*}{$\begin{array}{c}\chi^{2}(3,460)= \\
1.400\end{array}$} & \multirow{4}{*}{$\mathrm{P}=0.705$} \\
\hline & & Unemployed & $\begin{array}{c}36 \\
(62.1 \%)\end{array}$ & $\begin{array}{c}22 \\
(37.9 \%)\end{array}$ & & \\
\hline & & Housewife & $\begin{array}{c}43 \\
(60.6 \%)\end{array}$ & $\begin{array}{c}28 \\
(39.4 \%)\end{array}$ & & \\
\hline & & Retired & $\begin{array}{c}5 \\
(62.5 \%)\end{array}$ & $\begin{array}{c}3 \\
(37.5 \%)\end{array}$ & & \\
\hline & \multirow{4}{*}{2018} & Employed & $\begin{array}{c}240 \\
(49.6 \%)\end{array}$ & $\begin{array}{c}244 \\
(50.4 \%)\end{array}$ & \multirow{4}{*}{$\begin{array}{c}\chi^{2}(3,766)= \\
4.048\end{array}$} & \multirow{4}{*}{$\mathrm{P}=0.256$} \\
\hline & & Unemployed & $\begin{array}{c}62 \\
(41.3 \%)\end{array}$ & $\begin{array}{c}88 \\
(58.7 \%)\end{array}$ & & \\
\hline & & Housewife & $\begin{array}{c}46 \\
(46.9 \%)\end{array}$ & $\begin{array}{c}52 \\
(53.1 \%)\end{array}$ & & \\
\hline & & Retired & $\begin{array}{c}19 \\
(55.9 \%)\end{array}$ & $\begin{array}{c}15 \\
(44.1 \%)\end{array}$ & & \\
\hline
\end{tabular}

Source: [55] [57] and authors' calculations. 
On the other hand, the relation between employment status and the response to "Have you ever heard or read about colon cancer detection?"; and based on Chi-Square test of independence results depicted in Table 14 for the 2016 and 2018 data, is in fact independent. Therefore, the employment status of those individuals aware of CRC has no significant influence on the familiarity with CRC detection. Consequently, CRC detection awareness did not change along time under the employment status.

\section{Discussion}

Based on the two 2016 and 2018 cross-sectional samples, we demonstrate an increase in awareness of CRC among the Lebanese population. The percentage of those who have heard about CRC has increased significantly from 40.4\% in 2016 to $78.7 \%$ in 2018. In fact, it looks that the efforts of SAID NGO (118 different major activities in the span of 3 years) did make a significant difference in what relates to CRC awareness among the participant Lebanese population. However, among those who are aware of CRC, the percentage of those acquainted with CRC screening presented no improvement where the 2016 figure of $57.3 \%$ decreased significantly to $48.0 \%$ in 2018 . This result may be due to the fact that no organized screening is performed in Lebanon rather opportunistic screening is offered [1] (pp. 284-285).

In addition, the results of the research showed that the proportion of respondents who believed that family history is the major risk factor for CRC did increase significantly from $47.7 \%$ in 2016 to $90.8 \%$ in 2018 . This high percent for 2018 fits the finding by Baasiri et al. [56] who reported 70.1\% of the respondents "knew that the risk for developing CRC increases if they have a family member with CRC" (p. 171). In addition to the findings reported by IARC [1] whereby results from several European nations lead to the stated outcome, "There is a large body of evidence from observational studies, most of which have been summarized in meta-analyses, which consistently found an approximately 2 -fold increased risk of CRC in people with a first degree relative with CRC compared with people with no such family history" (p. 264). Likewise, the proportions of respondents who believed that overweight, age, and stress are among the major risk factors for CRC increased from $26.9 \%, 26.7 \%$ and $11.3 \%$ in 2016 to $86.2 \%$, $52.1 \%$ and $21.51 \%$ in 2018 , respectively. On the other hand, the proportions for the risk factors related to alcohol and smoking have dropped from $37.7 \%$ and $37.3 \%$ to $27.4 \%$ and $24.2 \%$, respectively.

Along the same line, the non-readiness and unwillingness for CRC screening has shown a decrease from $29.3 \%$ in 2016 down to $16.4 \%$ in 2018 (13.2\% did not agree that they are ready for CRC screening and 3.2\% strongly did not agree). Again, Baasiri et al. [56] report a $30.5 \%$ of the respondents being unwilling before the giant colon visit. In addition, the proportion of those who believe that they may reduce CRC risk has increased from $78.7 \%$ in 2016 to $96.0 \%$ in 2018 (70.9\% strongly agreed that they can lower their risk of and $25.1 \%$ agreed that 
they can).

Furthermore, the proportion of CRC aware respondents who have relatives diagnosed with CRC has dropped significantly from $22.8 \%$ to $9.9 \%$. This could indicate that NGO awareness campaigns have widened their target population to include more populations with undiagnosed CRC in their families. The proportion of those who intend to undergo a FIT test did increase significantly from $22.0 \%$ in 2016 to $66.5 \%$ in 2018 , which is a reassuring result.

The research outcomes showed that the proportion of those who intend to do nothing in relation to CRC screening became $16.8 \%$ of those aware of CRC (In $2016,77.3 \%$ of the sample refused colonoscopy, $84.2 \%$ of the sample refused virtual colonoscopy and $78.0 \%$ of the sample refused the FIT) and the proportion of those who intend to undergo a colonoscopy did decrease significantly from $22.7 \%$ in 2016 to $11.4 \%$ in 2018 . The aforementioned attitude is also observed in Baasiri et al. [56] finding who reported that "although the majority of the participants $>50$ years of age and eligible for CRC screening were willing to get screened $(74.2 \%)$, we found that only $14.2 \%$ reported having undergone CRC screening test in the previous years" (p. 171). Noteworthy as well the study performed by EL Kaddoum et al. [64], who concluded "while it was hard for us to quantify people for whom a free FIT was proposed, the low restitution rate among those who accepted to undergo the test shows the urgent necessity of establishing sensitization and screening campaigns" (p. S23).

The most important source of information for CRC was friends where the percentage of respondents who indicated this choice was $18.4 \%$ in 2016 which did increase considerably to $73.8 \%$ in 2018 . In second place came family (18.7\% chose family in 2016 which went up to $56.7 \%$ in 2018). Physicians occupied the third place as sources of information (18.9\% in 2016 and $40.2 \%$ in 2018), well this is not an encouraging outcome since physician recommendation happens to be the most important factor that influences "being up to date with screening and intending to be screened" [65]. This could indicate a low level of engagement with the healthcare system when it comes to preventative care.

As for media as a source of information, the research showed that media occupies a low position as a CRC information source where in 2016 only $22.6 \%$ of the respondents relied on media as a source of information on CRC, this percentage dropped to $13.7 \%$ in 2018 . The aforementioned outcome is possibly due to three factors, the recurring stressful political events in Lebanon, the COVID-19 situation and the habit of reading less [62] [63]. Such an observation must be taken in consideration when awareness campaigns are designed for the future to come.

As for gender differences, it looks that from 2016 to 2018, the population understanding of CRC has grown where back in 2016 females were more familiar than males, then by 2018 males have caught up.

In conclusion, CRC awareness is increasing over time and there is a trend towards more FIT CRC early screening tests. In addition, it looks that more 
masses are aware of CRC risk factors (overweight, age, and stress). It is noticeable that the proportion of those who believe that family history is a major CRC factor has almost doubled in the time interval between 2016 and 2018. It looks that the awareness campaigns are fortifying CRC knowledge.

\section{Conclusions and Recommendations}

This paper is the first contemporary research in Lebanon to perform a cross-sectional study of Lebanese residents' CRC awareness and compare the findings with those from an earlier study.

The justification of such a study emanates from the continuous flow of reports and studies addressing the importance of Colorectal Cancer Screening.

The basis for the current research was two papers reporting the use of several tools to motivate, create, increase and sustain the Lebanese population awareness about the great benefits of preventive screening for Colon Cancer. Among these tools, are public gatherings, conferences, workshops, visitations to rural communities, sport activities [marathons], university and school lectures, meetings with government officials, meetings with the Minister of Health, and the use of a giant Inflatable Colon (similar to [56] as a support vivid-tool for spreading awareness of Colorectal Cancer Screening [66] [67]. Further, this paper has its first merit from the comparative assessment of the collected and analyzed data and facts from all the aforementioned events; in addition, results and outcomes enrich the current scarcity of information about the topic.

According to Mamlouk et al. [16], CRC is naturally developed, as a malignant transformation of a benign adenoma in the majority of cases. Therefore, Bonnington and Rutter [17] argue that the aforementioned fact gives hope that the detection of adenomas and polyps with malignant potential could reduce the mortality rate. Thus, there is a continuous and urgent need to launch population-wide campaigns that assist to inform the Lebanese residents about cancer, the underlying risk factors, and the promising remedies [5] [55] [56] [57].

This study presents significant evidence that the cumulative use of more than 135 different activities by SAID NGO [68] including the use of a giant inflatable colon [tunnel like] increases knowledge of colorectal cancer and its corresponding screening practice. According to SAID's president, “These activities have directly affected 8000 people of all ages. A total of 1200 free FIT tests were performed and 95 colonoscopy procedures were performed, by the association, to anyone whose results were positive" [61]. The study shows that awareness of the importance of CRC screening did increase significantly from 40.4\% in 2016 [57] [69] to $78.7 \%$ in 2018 [55] [70]. Furthermore, since 2018, the implications of the dynamism of SAID NGO and other associations continued to produce more awareness campaigns based on the fact that the lack of awareness on CRC and its common risks and symptoms terminology is a barrier to CRC screening. Accordingly, the issue needs to be more highlighted among members of the society. Consequently, SAID NGO organized a walkathon [5 km march] on March 10, 
2019 under the slogan "be fit, do FIT" and an event's motto "March in Blue," in reference also to Colon Cancer Awareness Month and the blue color of the campaign's ribbons [71] [72]. See Figure 3.

The knowledge and the facts presented and gained from this study will continue to guide public policy makers in formulating and adjusting policies to promote awareness and support NGOs that are active in this field. It is worth mentioning that the previous extensive campaigns across the Lebanese territory and the continuous communication with health authorities in hospitals, NGOs, clinics, and political figures beside the Ministry of Public Health resulted in the launching of the first "National Colon Cancer Awareness Campaign 2019" supported by Dr. Jamil Jabbak, Minister of Public Health, and in cooperation with Merck Sharp and Dom, the Syndicate of Physicians, the Syndicate of Pharmacists, the Syndicate of Hospitals, the Lebanese Association of Oncologists, SAID NGO and other civil associations, and Medical Laboratory Owners In Lebanon [73].

Dr. Jamil Jabbak, Minister of Public Health, announced that the Rafik Hariri hospital will be presenting 1000 free FIT tests to those benefiting from the Ministry of Public Health's services (those without insurance). This grant is provided by Fuji Film International. Also, this is the first time that the Ministry of Public Health has launched a national campaign to raise awareness on colon cancer, something that was deemed necessary given the increasing numbers of patients. At the end of the announcement, an educational film prepared by the Ministry of Health, was screened, urging citizens to carry out FIT examinations every year. Furthermore, an informational pamphlet (see Figure 4) was launched to the public supported by the Lebanese Association of Gastroenterology, the Lebanese Society of Medical Oncology, the Ministry of Public Health, and surely SAID NGO (the only civil society organization in Lebanon that is specialized in raising awareness on the early detection of colon cancer) [61].

This study reflects current health education of several community groups,

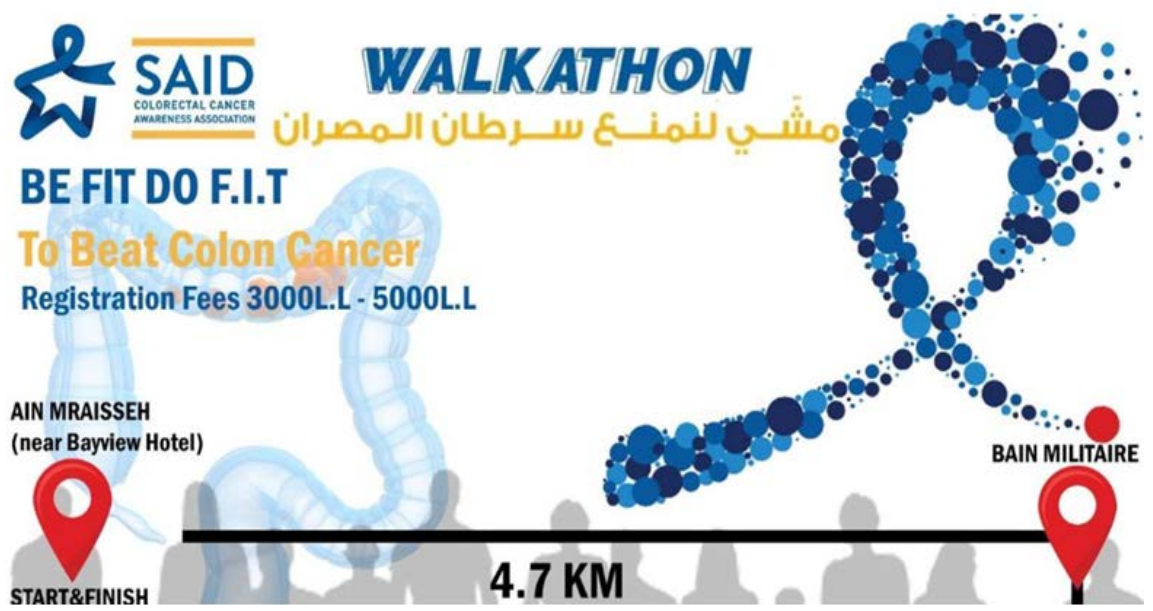

Figure 3. Walkathon with the logo "Be Fit, Do FIT" organized by SAID NGO. Source: [68] [74]. 


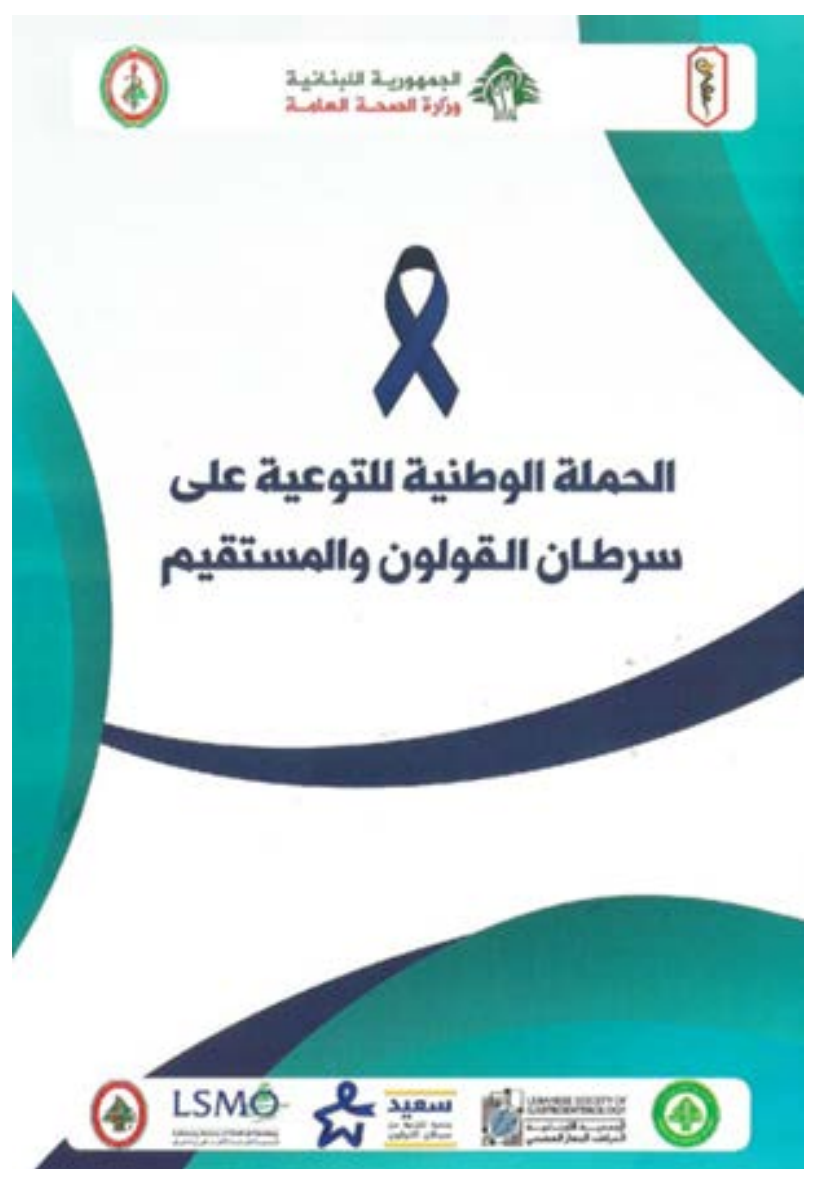

Figure 4. Pamphlet: National Colorectal Cancer Awareness Campaign. Source: [73].

which could help guide establishing local screening protocols, in addition, to inclusion in health provider curricula. Moreover, as the study guides policy makers in making and adjusting policies to achieve a more effective performance, it will help the specialized NGOs to grow, resulting in enhanced standards of living of the community at large. There is a continuous and urgent need to launch population-wide campaigns that assist to inform the Lebanese residents about cancer, the underlying risk factors, and treatments.

\section{Conflicts of Interest}

The authors declare no conflicts of interest regarding the publication of this paper.

\section{References}

[1] IARC (2019) Colorectal Cancer Screening. IARC Handbooks of Cancer Intervention, Vol. 17. International Agency for Research on Cancer, Lyon. https://publications.iarc.fr/573

[2] IARC (2020) Lebanon Fact Sheets: Globocan 2018. The Global Cancer Observatory. International Agency for Research on Cancer, Lyon.

https:/gco.iarc.fr/today/data/factsheets/populations/422-lebanon-fact-sheets.pdf 
[3] World Health Organization (2018) Latest Global Cancer Data: Cancer Burden Rises to 18.1 Million New Cases and 9.6 Million Cancer Deaths in 2018. International Agency for Research on Cancer (IARC): Press Release $\mathrm{N}^{\circ} 263$. https://www.who.int/cancer/PRGlobocanFinal.pdf

[4] The Global Cancer Observatory (2019) Globocan 2018. WHO, Producer, \& GCO. International Agency for Research on Cancer, Lyon. https://gco.iarc.fr/today/data/factsheets/populations/900-world-fact-sheets.pdf

[5] Khachfe, H.H., Salhab, H.A., Fares, M.Y. and Khachfe, H.M. (2020) Probing the Colorectal Cancer Incidence in Lebanon: An 11-Year Epidemiological Study. Gastrointest Cancer, 51, 805-812. https://doi.org/10.1007/s12029-019-00284-Z

[6] Ferlay, J., Soerjomataram, I., Dikshit, R., Eser, S., Mathers, C., Rebelo, M., et al. (2014) Cancer Incidence and Mortality Worldwide: Sources, Methods and Major Patterns in GLOBOCAN 2012. International Journal of Cancer, 136, E359-E386. https://doi.org/10.1002/ijc.29210

[7] IARC International Agency for Research on Cancer (2018) Press Release No. 263. Global Cancer Observatory. https://www.iarc.fr/wp-content/uploads/2018/09/pr263_E.pdf

[8] Arnold, M., Sierra, M.S., Laversanne, M., Soerjomataram, I., Jemal, A. and Bray, F. (2017) Global Patterns and Trends in Colorectal Cancer Incidence and Mortality. Gut, 66, 683-691. https://doi.org/10.1136/gutjnl-2015-310912

[9] Dénes, M.I., Nădășan, V., Molnar, C., Bancu, Ș., Borz, C.O. and Zoltán, Á. (2018) Is Awareness Enough to Bring Patients to Colorectal Screening? Open Medicine, 13, 528-533. https://doi.org/10.1515/med-2018-0077

[10] Siegel, R.L., Fedewa, S.A., Anderson, W.F., Miller, K.D., Ma, J., Rosenberg, P.S., et al. (2017) Colorectal Cancer Incidence Patterns in the United States, 1974-2013. Journal of the National Cancer Institute, 109, djw322. https://doi.org/10.1093/jnci/djw322

[11] Abou Rached, A., Khater, C., Aftimos, G., Khairallah, S. and Mokarbel, N. (2007) Les Cancers Digestif au Liban. JFHOD, Journées Francophones d'Hépato-gastroentérologie et d'Oncologie Digestive. https://www.snfge.org/content/les-cancers-digestifs-au-liban

[12] Shamseddine, A. (2015) Cancer Trends in Lebanon. Human \& Health, 32, 8-11.

[13] Kulhánová, I., Bray, F., Fadhil, I., Al-Zahrani, A.S., El-Basmy, A., Anwar, W.A., et al. (2017) Profile of Cancer in the Eastern Mediterranean Region: The Need for Action. Cancer Epidemiology, 47, 125-132. https://doi.org/10.1016/j.canep.2017.01.009

[14] Singh, H., Nugent, Z., Demers, A., Kliewer, E. and Mahmud, S. (2010) The Reduction in Colorectal Cancer Mortality after Colonoscopy Varies by Site and Cancer. Gastroenterology, 139, 1128-1137. https://doi.org/10.1053/j.gastro.2010.06.052

[15] Baxter, N., Goldwasser, M., Paszat, L., Saskin, R., Urbach, D. and Rabeneck, L. (2009) Association of Colonoscopy and Death from Colorectal Cancer. Annals of Internal Medicine, 150, 1-8. https://doi.org/10.7326/0003-4819-150-1-200901060-00306

[16] Mamlouk, S., Simon, T., Tomás, L., Wedge, D.C., Arnold, A., Menne, A., et al. (2020) Malignant Transformation and Genetic Alterations are Uncoupled in Early Colorectal Cancer Progression. BMC Biology, 18, 116. https://doi.org/10.1186/s12915-020-00844-x

[17] Bonnington, S.N. and Rutter, M.D. (2016) Surveillance of Colonic Polyps: Are We Getting It Right? World Journal of Gastroenterology, 22, 1925-1934. 
https://doi.org/10.3748/wjg.v22.i6.1925

[18] Kakushadze, Z., Raghubanshi, R. and Yu, W. (2017) Estimating Cost Savings from Early Cancer Diagnosis. Data (Basel), 2, 30. https://doi.org/10.3390/data2030030

[19] The American Cancer Society (2020) Colorectal Cancer Screening Tests. The American Cancer Society Medical and Editorial Content Team. https://www.cancer.org/cancer/colon-rectal-cancer/detection-diagnosis-staging/scre ening-tests-used.html

[20] Rim, S., Joseph, D., Steele, C., Thompson, T. and Seeff, L. (2011) Colorectal Cancer Screening United States, 2004, 2006, and 2008. Morbidity and Mortality Weekly Report Surveillance Summaries, 60, 42-46.

[21] Brandt, H.M., Dolinge, H.R., Sharpe, P.A., Hardin, J.W. and Berger, F.G. (2012) Relationship of Colorectal Cancer Awareness and Knowledge with Colorectal Cancer Screening. Colorectal Cancer, 1, 383-396. https://doi.org/10.2217/crc.12.45

[22] Whitlock, E.P., Lin, J., Liles, E., Beil, T., Fu, R., O’Connor, E., et al. (2008) Screening for Colorectal Cancer: An Updated Systematic Review [Internet]. Agency for Healthcare Research and Quality (US), Rockville.

[23] Mandel, J.S., Bond, J.H., Church, T.R., Snove, D.C., Bradley, G.M., Schuman, L.M., et al. (1993) Reducing Mortality from Colorectal Cancer by Screening for Fecal Occult Blood. Minnesota Colon Cancer Control Study. The New England Journal of Medicine, 328, 1365-1371. https://doi.org/10.1056/NEJM199305133281901

[24] Hardcastle, J.D., Chamberlain, J.O., Robinson, M.H., Moss, S.M., Amar, S.S., Balfour, T.W., et al. (1996) Randomised Controlled Trial of Faecal-Occult-Blood Screening for Colorectal Cancer. The Lancet, 348, 1472-1477. https://doi.org/10.1016/S0140-6736(96)03386-7

[25] Kronborg, O., Fenger, C., Olsen, J., Jørgensen, O.D. and Søndergaard, O. (1996) Randomised Study of Screening for Colorectal Cancer with Faecal-Occult-Blood Test. The Lancet, 348, 1467-1471. https://doi.org/10.1016/S0140-6736(96)03430-7

[26] Segnan, N., Armaroli, P., Bonelli, L., Risio, M., Sciallero, S., Zappa, M., et al. (2011) Once-Only Sigmoidoscopy in Colorectal Cancer Screening: Follow-Up Findings of the Italian Randomized Controlled Trial SCORE. Journal of the National Cancer Institute, 103, 1310-1322.

[27] Atkin, W.S., Edwards, R., Kralj-Hans, I., Wooldrage, K., Andrew, H.R., Northover, J.M., et al. (2010) Once-Only Flexible Sigmoidoscopy Screening in Prevention of Colorectal Cancer: A Multicentre Randomised Controlled Trial. The Lancet, 375, 1624-1633. https://doi.org/10.1016/S0140-6736(10)60551-X

[28] Yang, D., Gross, C., Soulos, P. and Yu, J. (2014) Estimating the Magnitude of Colorectal Cancers Prevented during the Era of Screening: 1976 to 2009. Cancer, 120, 2893-2901. https://doi.org/10.1002/cncr.28794

[29] Zorzi, M., Fedeli, U., Schievano, E., Bovo, E., Guzzinati, S., Baracco, S., et al. (2015) Impact on Colorectal Cancer Mortality of Screening Programmes Based on the Faecal Immunochemical Test. Gut, 64, 784-790. https://doi.org/10.1136/gutjnl-2014-307508

[30] Calonge, N., Petitti, D.B., DeWitt, T.G., Dietrich, A.J., Gregory, K.D., Harris, R., et al. (2008) Screening for Colorectal Cancer: U.S. Preventive Services Task Force Recommendation Statement. Annals of Internal Medicine, 149, 627-637. https://doi.org/10.7326/0003-4819-149-9-200811040-00243

[31] Levin, B., Lieberman, D.A., McFarland, B., Smith, R.A., Brooks, D., Andrews, K.S., et al. (2008) Screening and Surveillance for the Early Detection of Colorectal Cancer and Adenomatous Polyps. A Joint Guideline from the American Cancer Society, the 
US Multi-Society Task Force on Colorectal Cancer, and the American College of Radiology. CA Cancer Journal for Clinicians, 58, 130-160. https://doi.org/10.3322/CA.2007.0018

[32] Rex, D.K., Johnson, D.A., Anderson, J.C., Schoenfeld, P.S., Burke, C.A. and Inadomi, J.M. (2009) American College of Gastroenterology Guidelines for Colorectal Cancer Screening 2009 [Corrected]. American Journal of Gastroenterology, 104, 739-750. https://doi.org/10.1038/ajg.2009.104

[33] US Preventive Services Task Force (2008) Screening for Colorectal Cancer: US Preventive Services Task Force Recommendation Statement. Annals of Internal Medicine, 149, 627-637. https://doi.org/10.7326/0003-4819-149-9-200811040-00243

[34] Rim, S.H., Djenaba, J.A., Steele, C.B., Thompson, T.D. and Seeff, L.C. (2011) Colorectal Cancer Screening-United States, 2002, 2004, 2006, and 2008. The Morbidity and Mortality Weekly Report (MMWR) Supplements, 60, 42-46.

[35] Inadomi, J.M. and Sonnenberg, A. (2000) The Impact of Colorectal Cancer Screening on Life Expectancy. Gastrointestinal Endoscopy, 51, 517-523.

https://doi.org/10.1016/S0016-5107(00)70282-3

[36] Wong, G.Y., Lee, K.Y., Lam, K.F. and Fan, S.S. (2017) Community-Based Survey of Knowledge of Attitudes to and Practice of Colorectal Cancer Screening in Hong Kong. Journal of Digestive Diseases, 18, 582-590.

https://doi.org/10.1111/1751-2980.12544

[37] Niksic, M. and Forbes, L.J. (2018) Awareness of Colorectal Cancer: Recognition of Symptoms and Risk Factors by Socio-Demographic Characteristics. In: Olsson, L., Ed., Timely Diagnosis of Colorectal Cancer, Springer International Publishing, Berlin, 1-20. https://doi.org/10.1007/978-3-319-65286-3_1

[38] Raed, S.S., Yousif, Y.B., Alkhalifah, K.H. and Ali, L.M. (2018) Knowledge and Awareness of Colorectal Cancer among General Public of Kuwait. Asian Pacific Journal of Cancer Prevention, 19, 2455-2460.

[39] Su, T.T., Goh, J.Y., Tan, J., Muhaimah, A.R., Pigeneswaren, Y., Khairun, N.S., et al. (2013) Level of Colorectal Cancer Awareness: A Cross Sectional Exploratory Study among Multi-Ethnic Rural Population in Malaysia. BMC Cancer, 13, 376. https://doi.org/10.1186/1471-2407-13-376

[40] Al-Maghrabi, A.A. (2016) Assessment of the Knowledge and Awareness of Colorectal Cancer. International Journal of Academic Scientific Research, 4, 168-175.

[41] Alhomoud, S. (2018) Need for Colorectal Cancer Screening in Saudi Arabia. In: WEO, Ed., Colorectal Cancer Screening Committee Meeting, InterContinental Hotel, WEO, Vienna, 1-21.

[42] Al-Azri, M., Al-Hamedi, I., Al-Awisi, H., Al-Hinai, M. and Davidson, R. (2015) Public Awareness of Warning Signs and Symptoms of Cancer in Oman: A Community-Based Survey of Adults. Asian Pacific Journal of Cancer Prevention, 16, 2731-2737. https://doi.org/10.7314/APJCP.2015.16.7.2731

[43] Gimeno-García, A.Z., Quintero, E., Nicolás-Pérez, D. and Jiménez-Sosa, A. (2011) Public Awareness of Colorectal Cancer and Screening in a Spanish Population. Public Health, 125, 609-615. https://doi.org/10.1016/j.puhe.2011.03.014

[44] Salimzadeh, H., Sauvaget, C., Alamdari, R.A., Bishehsari, F. and Delvari, A. (2018) Knowledge, Attitude, and Practice of Iranian Physicians towards Colorectal Cancer Screening. Archives of Digestive Disorders, 2, 1-6.

[45] Bishehsari, F., Mahdavinia, M., Vacca, M., Malekzadeh, R. and Mariani, R. (2014) Epidemiological Transition of Colorectal Cancer in Developing Countries: Envi- 
ronmental Factors, Molecular Pathways, and Opportunities for Prevention. World Journal of Gastroenterology, 20, 6055-6072. https://doi.org/10.3748/wjg.v20.i20.6055

[46] Demyati, E. (2014) Knowledge, Attitude, Practice, and Perceived Barriers of Colorectal Cancer Screening among Family Physicians in National Guard Health Affairs, Riyadh. International Journal of Family Medicine, 2014, Article ID: 457354. https://doi.org/10.1155/2014/457354

[47] Moghimi-Dehkordi, B. and Safaee, A. (2012) An Overview of Colorectal Cancer Survival Rates and Prognosis in Asia. World Journal of Gastrointestinal Oncology, 4, 71-75. https://doi.org/10.4251/wjgo.v4.i4.71

[48] Omran, S., Barakat, H., Muliira, J.K. and Aljadaa, N. (2014) Knowledge, Experiences, and Barriers to Colorectal Cancer Screening: A Survey of Health Care Providers Working in Primary Care Settings. Journal of Cancer Education, 30, 53-61. https://doi.org/10.1007/s13187-014-0676-0

[49] Tfaily, M., Naamani, D., Kassir, A., Sleiman, S., Ouattara, M., Maocdieh, M., et al. (2019) Awareness of Colorectal Cancer and Attitudes towards Its Screening Guidelines in Lebanon. Annals of Global Health, 85, 75.

https://doi.org/10.5334/aogh.2437

[50] Arnold, C.L., Rademaker, A., Cooper, S., Esparza, J.M., Reynolds, C., Liu, D., et al. (2012) Literacy Barriers to Colorectal Cancer Screening in Community Clinics. Journal of Health Communication, 17, 252-264. https://doi.org/10.1080/10810730.2012.713441

[51] Gede, N., Kiss, D.R. and Kiss, I. (2018) Colorectal Cancer and Screening Awareness and Sources of Information in the Hungarian Population. BMC Family Practice, 19, Article No. 106. https://doi.org/10.1186/s12875-018-0799-1

[52] Geiger, T.M., Miedema, B.W., Geana, M.V., Thaler, K., Rangnekar, N.J. and Cameron, G.T. (2007) Improving Rates for Screening Colonoscopy: Analysis of the Health Information National Trends Survey (HINTS I) Data. Surgical Endoscopy, 22, 527-533. https://doi.org/10.1007/s00464-007-9673-2

[53] Kahi, C. (2018) Screening Start Age in Light of New ACS Guidelines. In: W. Organization, Ed., WEO Colorectal Cancer (CRC) Screening Committee Meeting, InterContinental Hotel, WEO, Vienna, 1-21.

[54] Larsen, M.B., Njor, S., Ingeholm, P. and Andersen, B. (2018) Effectiveness of Colorectal Cancer Screening in Detecting Earlier-Stage Disease-A Nationwide Cohort Study in Denmark. Gastroenterology, 155, 99-106. https://doi.org/10.1053/j.gastro.2018.03.062

[55] Hejase, A.J., Nemer, H., Hejase, H.J. and Honein AbouHaidar, G. (2018) Inflatable Colon: A Tool to Raise Awareness of the Importance of Colorectal Cancer Screening. IOSR Journal of Nursing and Health Science (IOSR-JNHS), 7, 58-67. https://doi.org/10.14322/publons.r2768485

[56] Baassiri, A., El-Harakeh, M., Itani, A., Nassar, F.J., Safi, R., Dassouki, Z., et al. (2020) Giant Inflatable Colon Model Enhances Lebanese Community Knowledge and Intention for Colorectal Cancer Screening. JCO Global Oncology, 6, 167-173. https://doi.org/10.1200/JGO.19.00274

[57] Nemer, H.A., Hejase, A.J., Hejase, H.J., Othman, M., Chawraba, M. and Trad, M. (2016) Colorectal Cancer: Exploring Awareness in Lebanon. The Journal of Middle East and North Africa Sciences, 2, 10-21. https://doi.org/10.12816/0032694

[58] Caruana, E.J., Roman, M., Hernández-Sánchez, J. and Solli, P. (2015) Longitudinal Studies. Journal of Thoracic Disease, 7, E537-E540. 
[59] Hejase, A.J. and Hejase, H.J. (2013) Research Methods: A Practical Approach for Business Students. 2nd Edition, Masadir Inc., Philadelphia.

[60] Nijhawan, L.P., Janodia, M.D., Muddukrishna, B.S., Bhat, K.M., Bairy, K.L., Udupa, N. and Musmade, P.B. (2013) Informed Consent: Issues and Challenges. Journal of Advanced Pharmaceutical Technology \& Research, 4, 134-140. https://doi.org/10.4103/2231-4040.116779

[61] Executive-Bulletin (2019) Under the Patronage and Presence of the Minister of Public Health Dr. Jamil Jabbak. https://executive-bulletin.com/health/under-the-patronage-and-presence-of-the-mi nister-of-public-health-dr-jamil-jabbak

[62] Hejase, A.J., Hejase, H.J., Younis, J. and Abbas, O. (2019) Reading Interests and Habits in Lebanon: Explorative Analysis. Saudi Journal of Humanities and Social Sciences, 4, 149-166.

[63] Hejase, A.J., Hejase, H.J., Chehimi, G. and Younis, J. (2020) Reading Habits in Lebanon and France: A Comparison. Journal of the Middle East and Africa Sciences, 6.

[64] EL Kaddoum, R., Roland, E., Haddad, F., Germanos, M., Mehawej, C., Kourie, H.R. and Kattan, J. (2019) The Results of 3000 FIT Tests: A Prospective Study Led at Saint Joseph University of Beirut. Lebanese Medical Journal, 67, S23. http://www.lebanesemedicaljournal.org/articles/67-A/doc10.pdf

[65] Walsh, J., Kaplan, C.P., Nguyen, B., Gildengorin, G., McPhee, S.J. and Pérez-Stable, E.J. (2004) Barriers to Colorectal Cancer Screening in Latino and Vietnamese Americans Compared with Non-Latino White Americans. Journal of General Internal Medicine, 19, 156-166. https://doi.org/10.1111/j.1525-1497.2004.30263.x

[66] Redwood, D., Provost, E., Asay, E., Ferguson, J. and Muller, J. (2013) Giant Inflatable Colon and Community Knowledge, Intention, and Social Support for Colorectal Cancer Screening. Preventing Chronic Disease, 10, E40. https://doi.org/10.5888/pcd10.120192

[67] Sanchez, J.I., Palacios, R., Cole, A. and O'Connell, M.A. (2014) Evaluation of the Walk-Through Inflatable Colon as a Colorectal Cancer Education Tool: Results from a Pre and Post Research Design. BMC Cancer, 14, 626. https://doi.org/10.1186/1471-2407-14-626

[68] Nasser, Z. (2019) Lebanon Marches to Raise Awareness on Colon Cancer. Annahar Website.

https://www.annahar.com/english/article/945386-lebanon-marches-to-raise-awaren ess-on-colon-cancer

[69] Zubaidi, A.M., AlSubaie, N.M., AlHumaid, A.A., Shaffi, S.A., AlKhayal, K.A. and AlObeed, O.A. (2015) Public Awareness of Colorectal Cancer in Saudi Arabia: A Survey of 1070 Participants in Riyadh. Saudi Journal of Gastroenterology, 21, 78-83. https://doi.org/10.4103/1319-3767.153819

[70] Briant, K.J., Wang, L., Holte, S., Ramos, A., Marchello, N. and Thompson, B. (2015) Understanding the Impact of Colorectal Cancer Education: A Randomized Trial of Health Fairs. BMC Public Health, 15, 1196. https://doi.org/10.1186/s12889-015-2499-2

[71] Daily Star (2019) Families Walk to Raise Awareness of Colon Cancer. http://www.dailystar.com.lb/News/Lebanon-News/2019/Mar-11/478498-families-w alk-to-raise-awareness-of-colon-cancer.ashx

[72] Civil Society Centre (2019) Families Walk to Raise Awareness of Colon Cancer. https://civilsociety-centre.org/collective/families-walk-raise-awareness-colon-cancer 
[73] Ministry of Public Health (2019) National Colon Cancer Awareness Campaign 2019.

https://www.moph.gov.lb/en/Pages/0/21009/national-colon-cancer-awareness-cam paign

[74] Lebanon24 (2020) Walk to Stop Colon Cancer: Returns in March [Arabic]. https://www.lebanon24.com/news/lebanon/675968/\%D9\%85\%D8\%B4\%D9\%91\%D 9\%8A-\%D9\%84\%D9\%86\%D9\%85\%D9\%86\%D8\%B9-\%D8\%B3\%D8\%B1\%D8\%B7 \%D8\%A7\%D9\%86-\%D8\%A7\%D9\%84\%D9\%85\%D8\%B5\%D8\%B1\%D8\%A7\%D9\% 86-\%D9\%8A\%D8\%B9\%D9\%88\%D8\%AF-\%D9\%81\%D9\%8A-\%D8\%A2\%D8\%B0\% D8\%A7\%D8\%B1 